Research Article

\title{
Time-Varying Compressive Strength Model of Aeolian Sand Concrete considering the Harmful Pore Ratio Variation and Heterogeneous Nucleation Effect
}

\author{
Yugen Li, ${ }^{1,2}$ Huimei Zhang $\mathbb{D}^{1,3}{ }^{1,3}$ Xoyu Liu, ${ }^{3}$ Guangxiu Liu, ${ }^{2}$ Dawei Hu, ${ }^{2}$ \\ and Xiangzhen Meng ${ }^{1}$ \\ ${ }^{1}$ College of Architecture and Civil Engineering, Xi'an University of Science and Technology, Xi'an, Shaanxi 710054, China \\ ${ }^{2}$ School of Architecture Engineering, Yulin University, Yulin, Shaanxi 719000, China \\ ${ }^{3}$ College of Sciences, Xi'an University of Science and Technology, Xi'an, Shaanxi 710054, China
}

Correspondence should be addressed to Huimei Zhang; zhanghmktz@xust.edu.cn

Received 10 July 2019; Revised 26 August 2019; Accepted 13 September 2019; Published 30 October 2019

Academic Editor: Ghassan Chehab

Copyright (c) 2019 Yugen Li et al. This is an open access article distributed under the Creative Commons Attribution License, which permits unrestricted use, distribution, and reproduction in any medium, provided the original work is properly cited.

\begin{abstract}
The aim of this study was to analyze the influence mechanism of aeolian sand on the mechanical property of concrete and establish the time-varying compressive strength model. Test studies on the development of concrete's compressive strength with aeolian sand from the $\mathrm{Mu}$ Us Desert were carried out. Influence mechanism of aeolian sand on the strength of concrete was revealed by using the nuclear magnetic resonance (NMR) to analyze the pore ratio and structures of aeolian sand concrete (ASC) and using the X-ray single crystal diffraction (XRD) to calculate the relative contents of hydration products semiquantitatively. Results show that the strength first increases and then decreases with the increase of aeolian sand content, where $20 \%$ was the best replacement ratio. With less than $20 \%$ content, it promoted the strength by changing the pore structure of concrete and accelerating the cement hydration speed based on its filling effect and chemical activity; when the content was more than $20 \%$, it led to a decrease of strength because of an increase of harmful pore ratio and a weakening of the interface transition zone (ITZ), where the stress concentration and damage when loading are easier to occur. At last, a time-varying compressive strength model of ASC considering the harmful pore ratio variation and heterogeneous nucleation effect was established based on the discussion, published date, and American Concrete Institute (ACI) model, which agrees well with the experimental results and can easily predict the strength of concrete.
\end{abstract}

\section{Introduction}

Sand is widely used as a fine aggregate material of concrete, and mainly river sand is used since a long time. With the continued increase in the scale of global infrastructure construction, there is insufficient sand of appropriate quality for construction, making it difficult to meet the needs of engineering construction. In China, there has been more than 20-fold increase in the annual use of construction sand in the past 30 years; the use is expected to grow at an annual rate of more than $20 \%$ [1]. Overall, the increased need has led to a shortage of river sand. The overexploitation of river sand has adverse effects on the ecological environment and also increases project cost [2]. The government has issued restrictions on the use of river sand, but the increased regulation has further aggravated the imbalance of supply and demand. Consequently, exploiting new sources of sand for construction to meet growing demand is an urgent problem in China and the world. One strategy is to use aeolian sand resources, and a second one is to use artificial sand. Aeolian sand has a good application prospect [3-5].

Aeolian sand, also known as desert sand or dune sand, is widely distributed around the world. China is one of the largest desert area countries, consisting of only the Mu Us sandy land, with an area of 39,800 square kilometers [6]. Studies have focused on wind breaking and sand fixing, but only recently have researchers begun to explore the use of aeolian sand as raw construction material. Early research 
examined how to mix the mortar and concrete by performing laboratory tests with standard test pieces. Jin et al. [7] showed that the aeolian sand can be used as fine aggregate material in concrete. Zhang et al. [8] found that the addition of a proper amount of water-reducing agent can significantly improve the workability and mechanical properties of concrete made with aeolian sand from the Tengger Desert. Khay et al. [9] determined the optimal mix ratio of compacted ASC by using some Sahara Desert sand to replace river sand, which broadened the source of materials that could be used for road concrete. Al-Harthy et al. [10] concluded that use of the appropriate amount of aeolian sand in place of river sand for mixing concrete improved the workability of the concrete without affecting its mechanical properties.

There are ongoing efforts to develop the theory of ASC, especially the influence mechanism of aeolian sand content on the technical characteristics of mortar and concrete. For example, Guettala and Mezghiche [11] studied the influence of aeolian sand powder on paste and found that replacement of some cement clinker with the aeolian sand powder can improve the compressive strength of the paste due to the physical, chemical, and physical-chemical properties of the sand powder. Luo et al. [12] showed that the very fine particles (VFPs) in aeolian sand can play a role in filling and volcanic ash and heterogeneous nucleation, changing the strength of the concrete. Liu et al. [6] analyzed the influence of impact load on ASC and found that aeolian sand has different filling effects on pores formed by coarse aggregates of different particle sizes and the concrete shows obvious size effect.

Research in this field is evolving from focus on standardbased specimens to analysis of components and structure. For example, Wang et al. [13] found that short columns and beams made with ASC exhibit a similar failure mode to that of constructs made from ordinary concrete. Ren et al. [14] showed that it is feasible to manufacture concrete-filled steel tubular columns with aeolian sand based on analysis of the compression properties of these columns, providing guidance for engineering with ASC.

Overall, much has been learned about ASC and its properties, but limitations remain. First, most studies have relied on indoor tests and are not comprehensive. Second, no compressive strength time-varying (strength-age) model of ASC has been reported. Additionally, the influence mechanism of aeolian sand content on the mechanical properties of concrete requires further analysis.

In this study, aeolian sand from the southern margin of $\mathrm{Mu}$ Us was used to mix concrete partly. The influence mechanism of aeolian sand content on the compressive strength of concrete was revealed by using XRD to test the phase composition and content and using NMR to measure the pore ratio and pore structure. Finally, a predictive model (time-varying) of ASC considering the harmful pore ratio variation and heterogeneous nucleation effect was established to guide engineering practice.

\section{Experiment Procedure}

2.1. Raw Materials. The sand used in this study includes both river and aeolian sand samples taken from three major sites (river sand from the mining plant of Xi'an, Shannxi Province, China; aeolian sand from two places called Shenmu and Yuyang in Yulin City, Shannxi Province, China; both of them were located on the edge of the Mu Us Desert). The main physical and chemical properties of the sand were determined and are shown in Tables 1 and 2, and the physical characteristics of them are shown in Figure 1. The coarse aggregate was crushed stone, with particle sizes of 5-20 mm, consisting three-part stone with a diameter range of $5-10 \mathrm{~mm}$ and seven-part stone with a diameter range of 10-20 mm. Ordinary Portland cement (P. O 42.5R) from Inner Mongolia Grassland Cement Company in China was used, and Table 3 lists the physical and mechanical properties.

2.2. Mix Proportions of ASC. Using ordinary concrete with a required strength of $40 \mathrm{MPa}$ as the baseline (sample $\mathrm{A}$ ), concrete samples were prepared in which a fraction of the river sand mass $(10 \%, 20 \%, 30 \%, 40 \%, 50 \%$, and $100 \%)$ was replaced by aeolian sand with a sand rate of 0.32 and a water-to-cement ratio (w/c) of 0.45 based on the Chinese technical code JGJ55-2011 [15] and designated as samples B, C, D, E, F, and G, respectively. There were four pieces per sample at each curing age except sample A with sixty pieces at an age of 28 days. Table 4 presents the mix proportion and materials used in this study as well.

2.3. Test Methods. Cube specimens $100 \mathrm{~mm} \times 100 \mathrm{~mm} \times$ $100 \mathrm{~mm}$ in size were molded, cured at $20^{\circ} \mathrm{C}$ for 24 hours, and then demolded. Next, the specimens were cured at standard conditions at $20 \pm 2^{\circ} \mathrm{C}$ with humidity of at least $95 \%$ on the basis of Chinese testing code GB/T50081-2002 [16]. Samples were removed at $3,7,14,21,28,35$, and 42 days, and the compressive strength was tested with a microcomputer electrohydraulic pressure testing machine (YAW-2000B) according to Chinese testing code GB/T50081-2002 [16] to analyze the macroscopic mechanical properties. The porosity and pore size distribution were measured by NMR. The phase composition and relative content of hydration products formed by different samples were analyzed by XRD to further determine the influence mechanisms of aeolian sand content on the compressive strength of concrete. The main test flow chart is shown in Figure 2.

\section{Test Results and Discussion}

3.1. Results. Figures 3 and 4 show the relationships among the concrete compressive strength, the aeolian sand content, and the length of curing. As can be seen in Figure 3, the compressive strength of concrete first increased and then decreased with increasing aeolian sand content at different curing ages; that is to say, there is a threshold. The maximum compressive strength value occurred for the sample C (20\%), and the results are higher than that of sample A (0\%) while the amount is no more than $30 \%$.

As shown in Figure 4, the growth rate of concrete compressive strength was obviously faster in the early curing process, with the growth rate faster in the first seven days 
Table 1: Physical properties of used sand.

\begin{tabular}{lccccc}
\hline Samples & Bulk density $\left(\mathrm{kg} / \mathrm{m}^{3}\right)$ & Apparent density $\left(\mathrm{kg} / \mathrm{m}^{3}\right)$ & Fineness modulus $\left(\mathrm{kg} / \mathrm{m}^{3}\right)$ & Clay content (\%) & Water absorption $(\%)$ \\
\hline River sand & 1556 & 2580 & 2.3 & 2.5 & 0.8 \\
Shenmu sand & 1564 & 2605 & 1.5 & 1.5 & 1.5 \\
Yuyang sand & 1548 & 2592 & 0.9 & 1.2 & 2.1 \\
\hline
\end{tabular}

TABle 2: Main chemical composition of the used sand.

\begin{tabular}{lccccccc}
\hline Samples & $\mathrm{SiO}_{2}$ & $\mathrm{Al}_{2} \mathrm{O}_{3}$ & $\mathrm{CaO}$ & $\mathrm{Fe}_{2} \mathrm{O}_{3}$ & $\mathrm{MgO}$ & Others & $\begin{array}{c}\mathrm{pH} \\
\text { value }\end{array}$ \\
\hline River sand & 79.57 & 6.4 & 2.97 & 7.88 & 1.07 & 1.91 & 7.05 \\
Yuyang sand & 78.85 & 8.02 & 4.79 & 6.22 & 1.15 & 0.97 & 7.41 \\
Shenmu sand & 80.88 & 7.43 & 3.28 & 6.83 & 0.69 & 0.89 & 7.49 \\
\hline
\end{tabular}

compared to the rate in the middle and later stages. Each specimen showed higher strength than the baseline material (0\%) for the first seven days except for G (100\%). The strength of the baseline material (0\%) increased gradually in the middle and later stages, but still exhibited a lower value than samples $\mathrm{B}, \mathrm{C}$, and $\mathrm{D}$ (with aeolian sand content of $10 \%-30 \%$ ). For samples E, F, and G, although the strengths of these materials were lower than that of the baseline material $(0 \%)$, they were still higher than the design value of $40 \mathrm{MPa}$. The growth rate of concrete strength became stable after 28 days. Compared with sample A (0\%), the compressive strength of sample C (20\%) was $15 \%$ higher at a curing age of three days, $11 \%$ higher at seven days, $8 \%$ higher at 28 days, and $6.7 \%$ higher at 42 days.

3.2. Discussion. The result presented above shows that the aeolian sand can affect the strength of concrete. It is consistent with the previous studies of Tayeb et al. [17] and Dong et al. [18]; that is to say, a proper amount of aeolian sand is good for the strength and durability of concrete. But it differs from the studies of Al-Harthy et al. [10] and Yusuf and Billihaminu [19], who found that aeolian sand just had negative effect on the strength of concrete. The reasons are due to its different physical properties (e.g., particle shape and size, specific surface area, and water absorption) and mineral composition because the engineering characteristics of aeolian sand vary from a particular place to another [19].

3.2.1. Increase of Strength. The discussion about the influence mechanism of aeolian sand on the concrete strength begins with the initial increase of strength with increasing aeolian sand content (at most 20\%). Three factors may contribute to it. First, addition of an appropriate amount of aeolian sand can improve the aggregate particle gradation and microstructure of ITZ of concrete in line with its small particle size (as shown in Figure 1(b)), which makes the cement granules, aeolian sand, river sand, and the stones form a continuous gradation accumulation system. So the particles of different sizes can be wrapped interstitially: fine sand, such as aeolian sand, is wrapped by the cement particles; the coarse sand and small stones are wrapped by the mortar; and the stone slurry is wrapped with big aggregates [20]. As a result, the internal porosity is reduced [18], which is of great importance to the increase of strength.

Second, addition of aeolian sand can increase the cohesive force between the slurry and stone and accelerate the speed of the cement hydration reaction based on its high specific surface area (as can be seen by comparing Figure 1(d) with Figure 1(e)) and weak alkaline property $[7,18]$. It can not only increase the bonding area between the slurry and stones but also make the cement particles more evenly distributed in the aggregates. Thus, the hydration space is increased, and the hydration speed is accelerated. Meanwhile, it increases the environmental alkalinity (as shown in Table 2, the aeolian sand have $\mathrm{pH}$ values of 7.41 and 7.49 , respectively) and promotes the formation of hydrated gelation products such as hydrated calcium silicate (C-S-H) and hydrated calcium aluminate (C-A-H), especially the $\mathrm{C}-\mathrm{S}-\mathrm{H}$ with high $\mathrm{Ca} / \mathrm{Si}$. These gelation products interweave into a network and so the strength changes.

In addition, water-cement ratio is an important influencing factor of concrete strength, and its value is inversely related to the strength. A certain amount of aeolian sand can reduce the effective water-cement ratio in the system, consistent with its stronger water absorption (as can be seen in Table 1), which can increase the strength of concrete with fixed water consumption.

3.2.2. Decrease of Strength. Figure 3 also presents the strength of the concrete decreasing with addition of excessive aeolian sand content; the reasons are as follows: First, it acts as the main aggregate instead of filling the internal structure of concrete, so the interference effect on the aggregate is weakened. An arch bridge effect between the small particles such as cement and aeolian sand is formed, which is extruded easily to form pores [21]. This causes the initial damage of effective load area and is harmful to the increase of concrete.

Then, the excessive water absorption decreases the water content in the system. When the sand ratio and water consumption were fixed, it leads to a decrease of slurry amount used to fill the pores formed by different grades and an increase of slurry consistency, which causes an increase of pore ratio and the content of big pores, as well as a weak ITZ. The stress concentration phenomenon is easier to occur around the pores, and the ITZ is the vulnerable place when loading, which speeds up the damage of concrete.

Moreover, the aeolian sand was weathered by some loose rocks, which has lower strength than river sand. This also reduces the macroscopic mechanical properties of concrete [22]. Even though it may promote the cement hydration reaction to some extent, its effect is weak because of the 


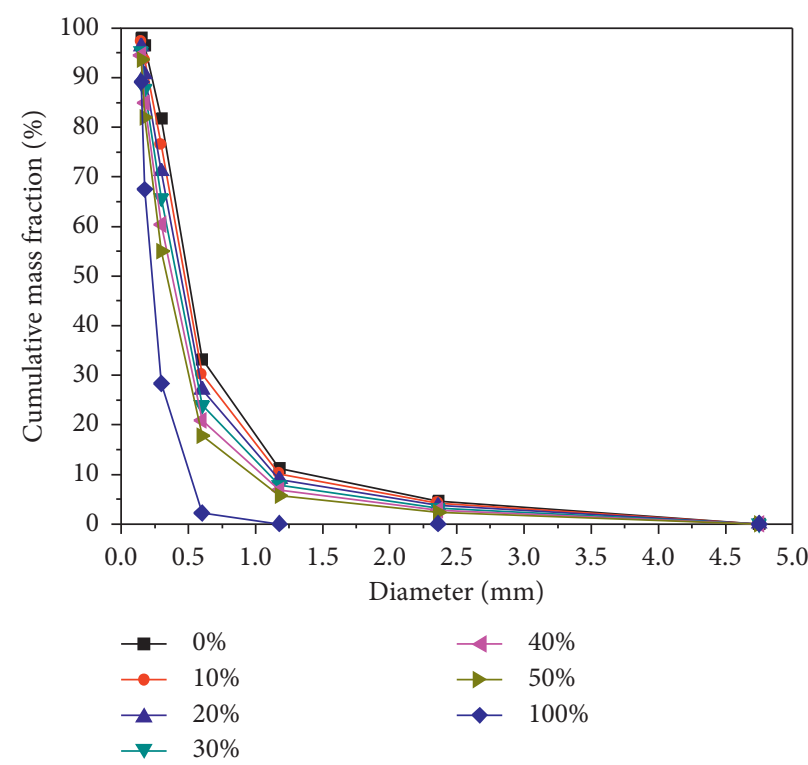

(a)

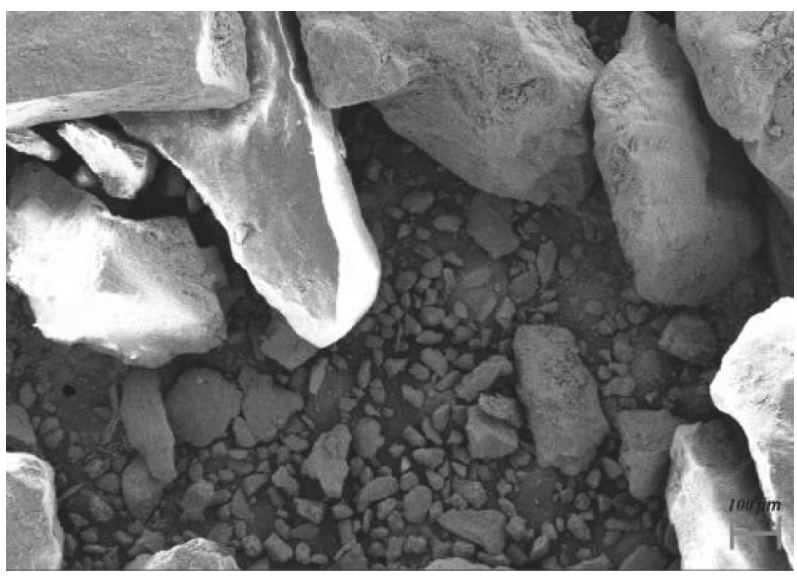

(c)

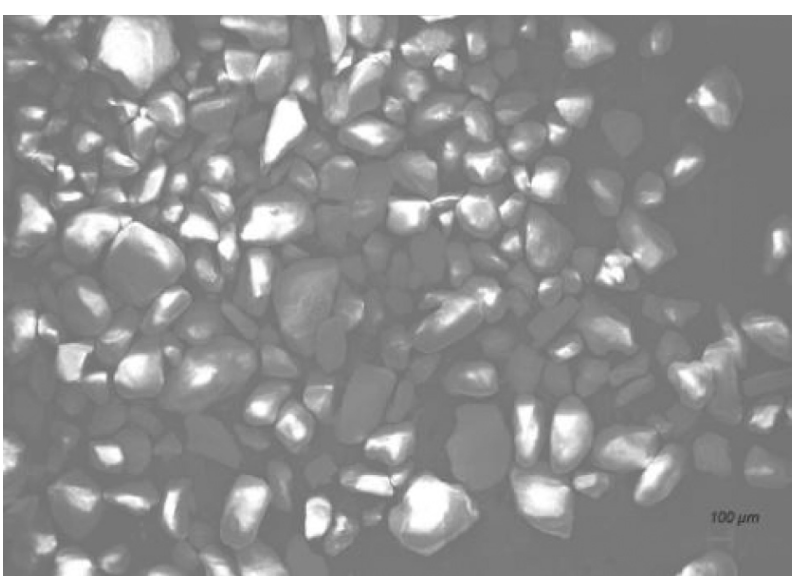

(b)

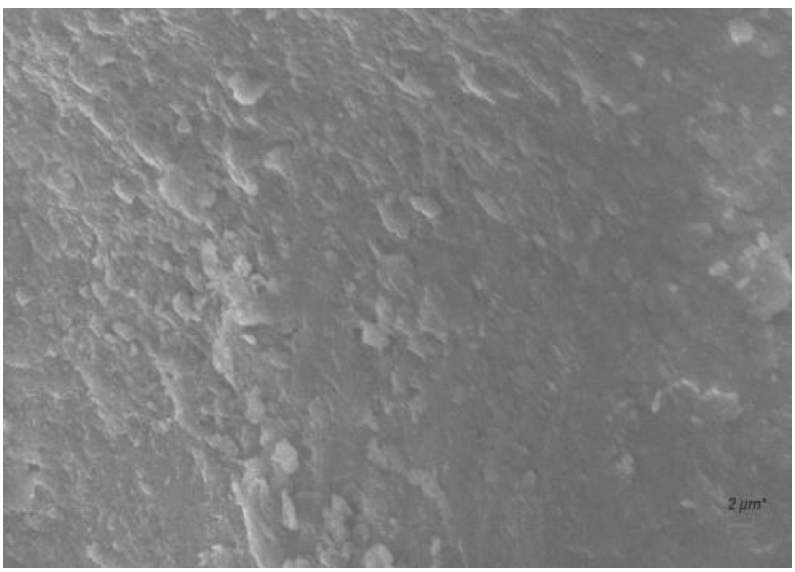

(d)

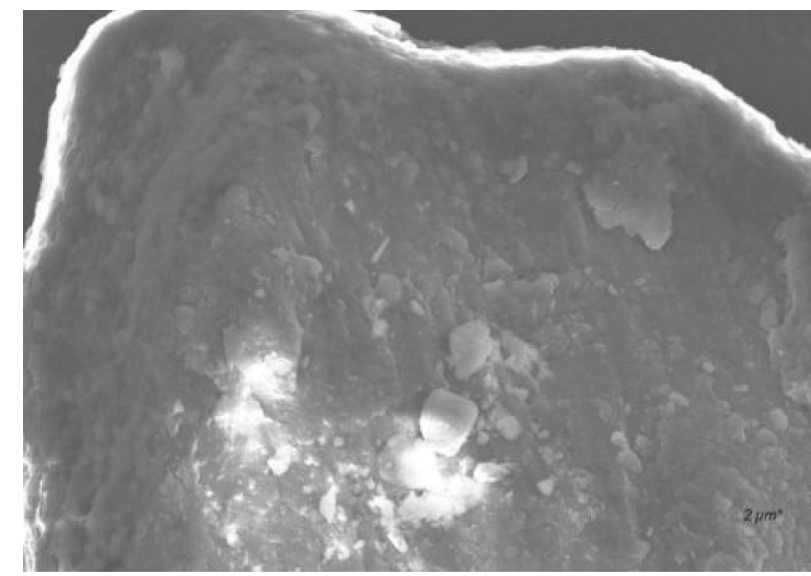

(e)

FIgure 1: Physical characteristics of the used sand. (a) Particle size distributions of each sample. (b) Aeolian sand SEM image (100 $\mu$ m). (c) River sand SEM image $(100 \mu \mathrm{m})$. (d) Microscopic appearance of river sand ( $2 \mu \mathrm{m})$. (e) Microscopic appearance of aeolian sand $(2 \mu \mathrm{m})$.

silicon-rich layer effect existed on the surface of the cement particles, which probably slows down the hydrolysis of $\mathrm{C}_{3} \mathrm{~S}$ and the formation of $\mathrm{C}-\mathrm{S}-\mathrm{H}$ and $\mathrm{C}-\mathrm{A}-\mathrm{H}$. So the strength increment is not enough to compensate for the negative effect caused by the change of pore physical structure and material property. 
TABLe 3: Physical and mechanical properties of used cement.

\begin{tabular}{lcccccc}
\hline & & & & Setting time (min) & \multicolumn{2}{c}{$\begin{array}{c}\text { Compressive strength } \\
(\mathrm{MPa})\end{array}$} \\
Density $\left(\mathrm{kg} / \mathrm{m}^{3}\right)$ & Standard water consumption $(\%)$ & Cubage stability & Initial & Final & 3 days & 28 days \\
\hline 3145 & 28.6 & Qualified & 135 & 179 & 23.5 & 56.1 \\
\hline
\end{tabular}

TABLE 4: Mix and material consumption of ASC.

\begin{tabular}{|c|c|c|c|c|c|c|c|}
\hline \multirow[t]{2}{*}{ Samples } & \multirow[t]{2}{*}{ Water $\left(\mathrm{kg} / \mathrm{m}^{3}\right)$} & \multirow[t]{2}{*}{ Cement $\left(\mathrm{kg} / \mathrm{m}^{3}\right)$} & \multirow[t]{2}{*}{ River sand $\left(\mathrm{kg} / \mathrm{m}^{3}\right)$} & \multicolumn{2}{|c|}{$\begin{array}{l}\text { Aeolian sand } \\
\left(\mathrm{kg} / \mathrm{m}^{3}\right)\end{array}$} & \multirow[t]{2}{*}{ Aggregate $\left(\mathrm{kg} / \mathrm{m}^{3}\right)$} & \multirow[t]{2}{*}{ Air entraining agent $\left(\mathrm{kg} / \mathrm{m}^{3}\right)$} \\
\hline & & & & Shenmu & Yuyang & & \\
\hline A $(0 \%)$ & 195 & 435 & 565 & 0 & 0 & 1205 & 0.02 \\
\hline B (10\%) & 195 & 435 & 508.5 & 28.3 & 28.3 & 1205 & 0.02 \\
\hline C (20\%) & 195 & 435 & 452 & 56.5 & 56.5 & 1205 & 0.02 \\
\hline $\mathrm{D}(30 \%)$ & 195 & 435 & 395.5 & 84.7 & 84.7 & 1205 & 0.02 \\
\hline E $(40 \%)$ & 195 & 435 & 339 & 113 & 113 & 1205 & 0.02 \\
\hline F (50\%) & 195 & 435 & 282.5 & 141.3 & 141.3 & 1205 & 0.02 \\
\hline$G(100 \%)$ & 195 & 435 & 0 & 282.5 & 282.5 & 1205 & 0.02 \\
\hline
\end{tabular}

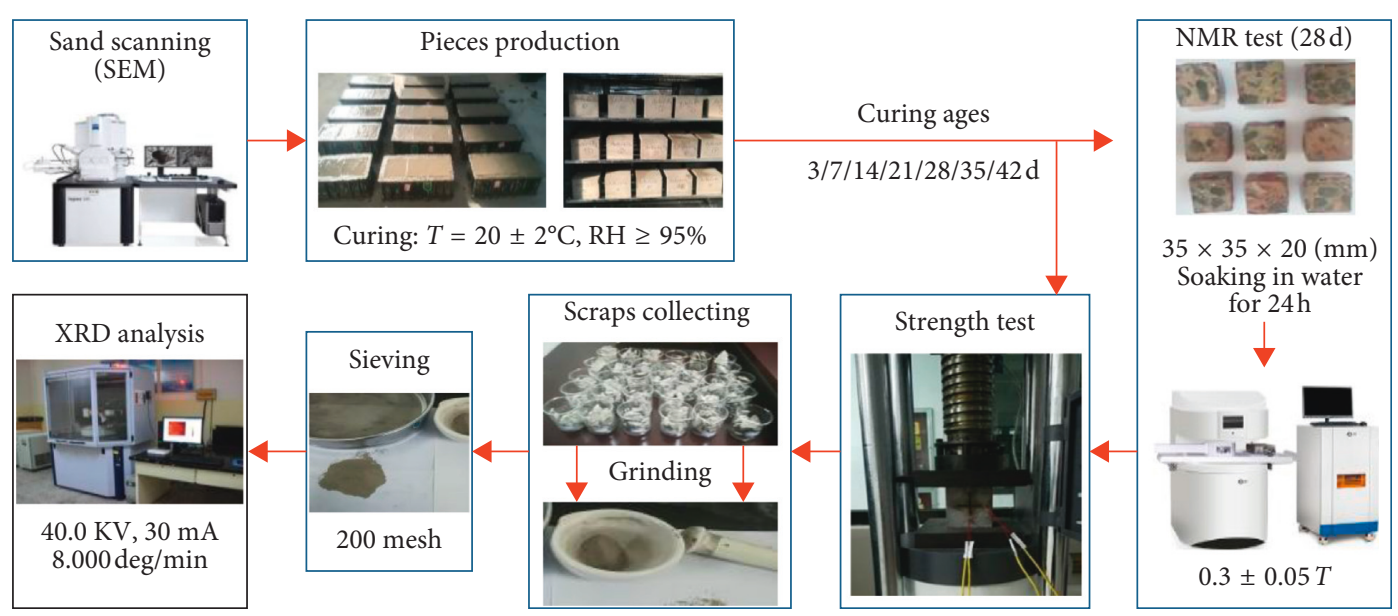

Figure 2: Main test flow chart.

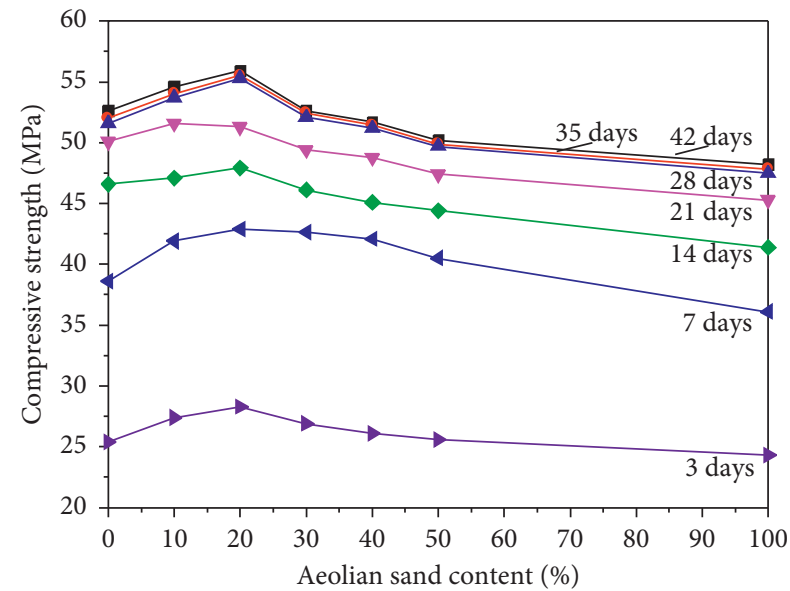

FIGURE 3: Relation between compressive strength and aeolian sand content.

In general, the double effect (promoted and reduced) of aeolian sand on the compressive strength of concrete can be attributed to the change of the porosity and pore structure and the speed of hydration reaction, which will be further revealed in the following sections.

\subsection{Influence Mechanism}

3.3.1. Pore Structures of ASC. Internal pore structure morphology was determined to describe the effect of aeolian sand addition on the mechanical property of concrete. A representative sample with a size of approximately $35 \mathrm{~mm} \times 35 \mathrm{~mm} \times 20 \mathrm{~mm}$ was cut out from the center of the test pieces after curing for 28 days (Figure 5 shows the cutting process of test piece). The porosity and internal pore structures of the samples were determined after drying to constant weight, drying under vacuum, and then soaking in water to saturation. The samples were then subjected to NMR (MacroMR12-150H-I). Figure 6 shows the relationship between porosity and aeolian sand content, and Figure 7 shows the $T_{2}$ spectrum distribution curve. The pore size distribution curve of the sample is also presented in Figure 8 to analyze the effect of aeolian sand on the strength 


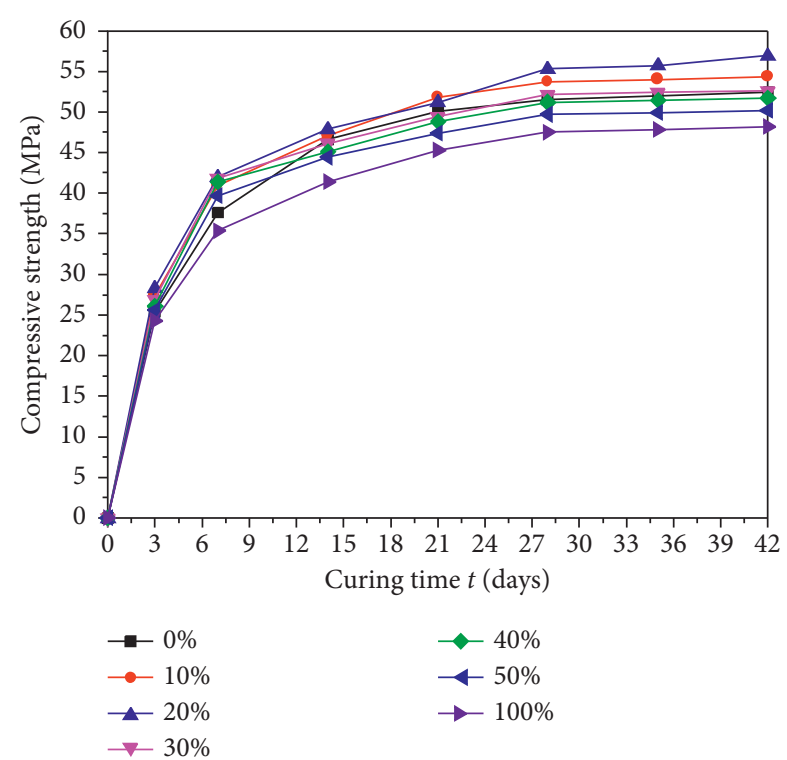

FigURE 4: Relation between compressive strength and curing ages.

of concrete. The relationship between the $T_{2}$ spectrum distribution curve and the pore size distribution of $r_{c}$ can be described by the following equation $[23,24]$ :

$$
\frac{1}{T_{2}}=5 \cdot \frac{3}{1000 r_{c}},
$$

where $T_{2}$ is the relaxation time (ms) and $r_{c}$ is the radius of pore $(\mu \mathrm{m})$.

As can be seen from Figure 6, the total porosity of concrete is high due to the influence of air entraining agent. The value first decreases and then increases with the increase of aeolian sand content, which is opposite to the change between the strength and aeolian sand content, but both processes exhibit a turning point near $20 \%$. Sample D (30\%), however, differs from this pattern and has a higher porosity than that of sample E, which may be due to vibrating, curing, or processing of the sample. The influence mechanism of aeolian sand content on concrete porosity is further analyzed below.

As shown in Figure 7, each sample exhibits a relaxation time of $0.01-10000 \mathrm{~ms}$, with a pore measurement range of $0.00015-150 \mu \mathrm{m}$ according to equation (1), but differs in peak position, intensity, and width. Table 5 lists the ratio of each peak area to the total peak area for the different samples presented in Figure 7, and the corresponding pore size distributions are presented in Figure 8.

From Table 5, we can see that the ratio of the first peak area to the total area in each sample is from $76.83 \%$ to $83.49 \%$. It indicates that the smaller pores (with pore radius of $0.00024-0.0415 \mu \mathrm{m}$ as shown in the third column of Table 5) make up the majority of each sample. Sample C $(20 \%)$ has the maximum value, and the baseline $(0 \%)$ has the minimum value. To be specific, the baseline $(0 \%)$ has five peaks, and the first three peaks area make up more than $98 \%$ of the total area, but there are a few large holes (maximum pore radius of $44.491 \mu \mathrm{m})$. Sample C (20\%) exhibits three peaks and has the lowest relative intensity of each peak and a maximum pore radius of $34.907 \mu \mathrm{m}$ (the smallest). Therefore, this material has close-grained structure and the highest macroscopic intensity. In samples F and G (greater than $20 \%$ of aeolian sand content), the percent of the first peak area decreased, the percent of the third and fourth peaks area increased, and the peaks shifted slightly right. Thus, the content of the large pores increased gradually, but the maximum value was still less than that in the baseline $(0 \%)$. The results indicate that the presence of aeolian sand can change the internal pore structure and affect the macroscopic mechanical properties of the concrete.

Different pore sizes have different effects on the mechanical properties of concrete. Mehta [25] found that the strength of concrete was affected only by pore diameter that exceeded $100 \mathrm{~nm}$. Xu et al. [26] reported that pores with a diameter of at least $200 \mathrm{~nm}$ had the main influence on the decline of concrete strength. In a study by a member of the China Engineering Academy, Wu [27] considered concrete pores with diameters smaller than $20 \mathrm{~nm}$ harmless, between 20 and $50 \mathrm{~nm}$ less harmful, 50-200 $\mathrm{nm}$ harmful, and larger than $200 \mathrm{~nm}$ more harmful. We calculated the diameter distribution of different types of pores in Figure 8, according to literature [27] by using the ratio of different aperture areas shown in $T_{2}$ spectrum to the total peak area, and the results are shown in Figure 9.

It can be seen from the results presented in Figure 9 that the pores in concrete are mainly harmless pores, which make up about $55 \%-62 \%$ of the total pore ratio. It changes with an initial increase and then decreases as the aeolian sand content increases. The ratio of less harmful pores and harmful pores account for about $16 \%-21 \%$ and $7 \%-10 \%$ of the total pore ratio, respectively. The more harmful pores, with the maximum impact on the strength of concrete, account for $15 \%-17 \%$ ratio of pores and exhibit a tendency of initial decrease and then increases with the increase in aeolian sand content. This is true for all samples, except for sample D (30\%) exhibiting lower harmless pores and higher more harmful pores (may be related to other factors, such as differences in vibration or maintenance). The physical structure of pores presented above agrees well with the compressive strength of concrete except for the $30 \%$ sample. This indicates that the concrete strength may be determined by both the distribution of pore size and the total pore ratio.

The reasons why an appropriate amount of aeolian sand particle perfects the internal structure of concrete can be analyzed as follows: First, the aeolian sand plays a role of ball bearing effect to reduce the friction between the slurry and aggregate, speeds up the fluidity of slurry, and can easily enter the internal concrete than river sand (which has angular or awkward shape and big size as shown in Figure 1(c)). This can not only reduce the wall effect and formation of water bladder and improve the microstructure of ITZ (which has high pore ratio than the cement stone) $[28,29]$ but also divide the large pores generated during the production process of concrete into small, nonconnected pores, which is conducive to form the small pores such as gel holes and reduce the pore ratio of cement stone $[10,21]$. 


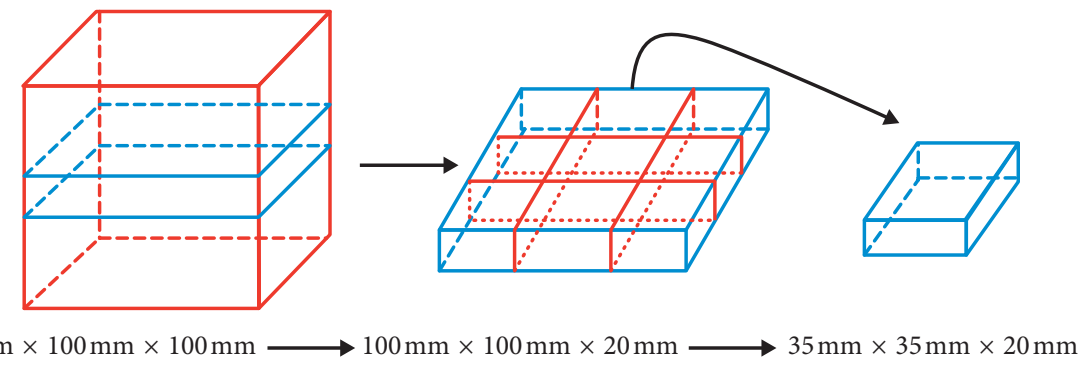

FIGURE 5: Cutting process of the NMR test piece.

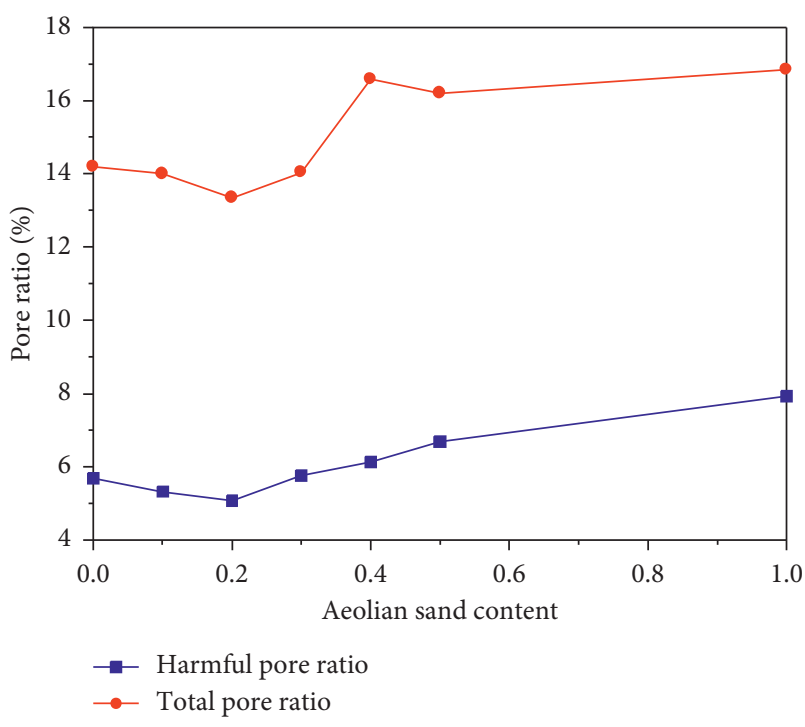

FIGURE 6: Relationship between pore ratio and aeolian sand content.

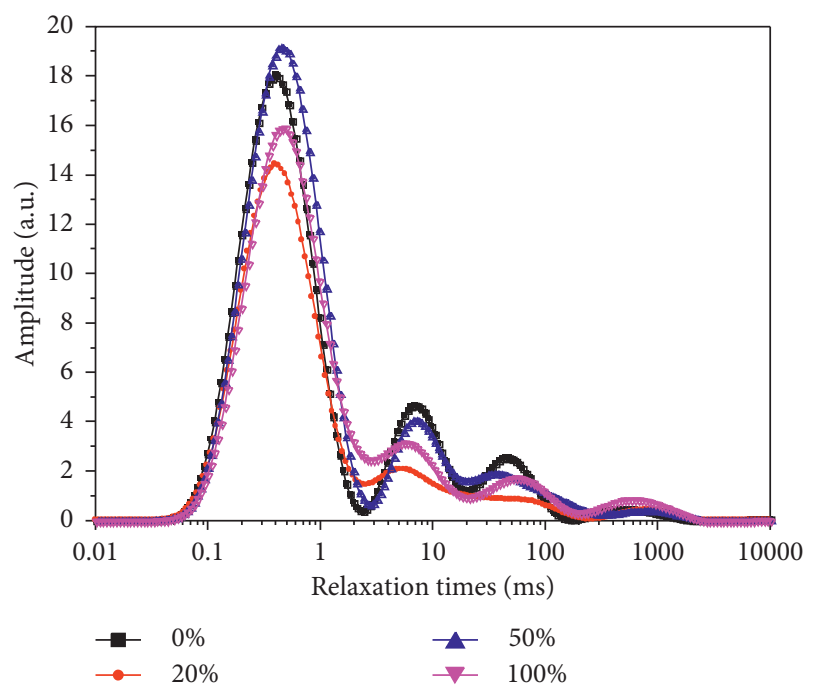

Figure 7: $T_{2}$ spectrum distribution curves.

In addition, the aeolian sand promotes a more even distribution of the cement particles on the aggregate surface, which accelerates the hydration reaction rate, improves the hydration crystallinity, and changes the content of hydrated

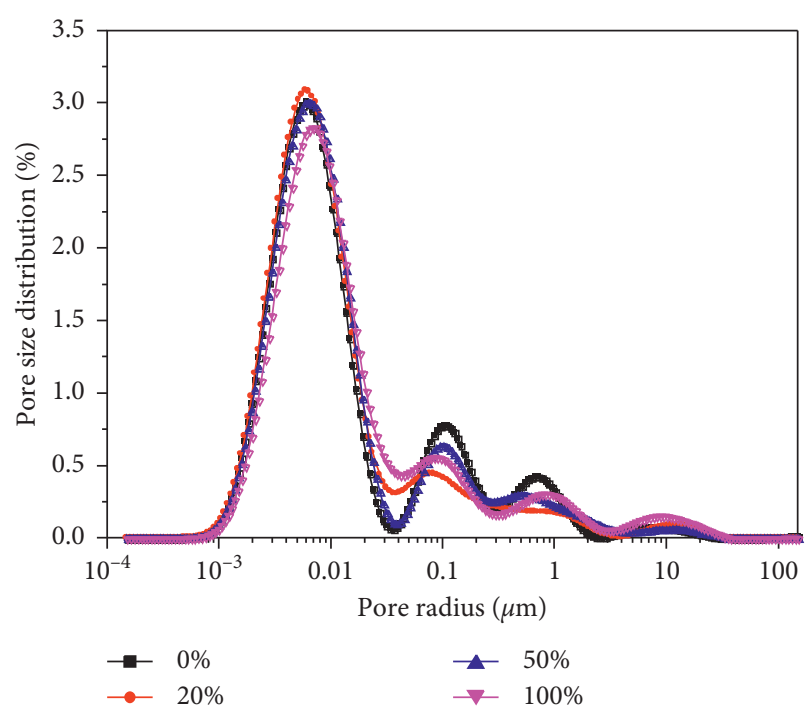

Figure 8: Pore size distribution curves of samples.

gelled products such as $\mathrm{C}-\mathrm{S}-\mathrm{H}$ and $\mathrm{C}-\mathrm{A}-\mathrm{H}$ due to its high specific surface area and chemical properties. This increases the volume of the gelation products used to fill the pores of concrete and reduces the pore size and shrinking deformation of cement stone when other things are being equal. So an increase of harmless pores and decrease of more harmful pores occur, which benefit the macroscopic strength of concrete.

The opposite trend occurs when too much aeolian sand is added. It reduces the content of water in the system, increases ion concentration in the slurry, and enlarges the contact area between the fine aggregates and paste [10]. Therefore, the amount of slurry used for filling pores of different grades and coating the surface of the aggregates is reduced, and the fluidity is decreased and the viscosity is increased, which result in a decrease of the cement stone density and a large shrinkage deformation, especially the ITZ between the mortar and aggregate, as well as the ITZ between the sand and cement paste. Moreover, there exists microzone bleeding effect around the aggregate, and the worse the gradation is, the more obvious the bleeding effect $[30,31]$. An excessive addition of aeolian sand makes a poor gradation of aggregate, which increases the bleeding effect, especially the bottom of large aggregates. This results in a decrease of harmless pore ratio and an increase of harmful pore ratio, as well as a weakened ITZ and high pore ratio. 
TABLE 5: Nuclear magnetic resonance $T_{2}$ spectrum areas and pore size distribution of ASC.

\begin{tabular}{lcccccccccc}
\hline \multirow{2}{*}{ Samples } & \multicolumn{3}{c}{ Peak1 } & \multicolumn{2}{c}{ Peak2 } & \multicolumn{2}{c}{ Peak3 } & \multicolumn{2}{c}{ Peak4 } & \multicolumn{2}{c}{ Peak5 } \\
& Percent & Pore size $(\mu \mathrm{m})$ & Percent & Pore size $(\mu \mathrm{m})$ & Percent & Pore size $(\mu \mathrm{m})$ & Percent & Pore size $(\mu \mathrm{m})$ & Percent & Pore size $(\mu \mathrm{m})$ \\
\hline $0 \%$ & 76.83 & $0.000275-0.0361$ & 13.90 & $0.0387-0.290$ & 7.56 & $0.311-2.495$ & 0.77 & $2.675-7.579$ & 0.86 & $8.124-44.491$ \\
$20 \%$ & 83.49 & $0.000275-0.0387$ & 14.81 & $0.0415-3.785$ & 1.70 & $4.057-34.907$ & - & - & - & - \\
$50 \%$ & 79.86 & $0.000275-0.0388$ & 11.64 & $0.0415-0.290$ & 7.29 & $0.311-4.662$ & 1.21 & $4.997-34.912$ & - & - \\
$100 \%$ & 78.01 & $0.00024-0.0415$ & 11.70 & $0.0445-0.311$ & 6.78 & $0.333-3.074$ & 3.51 & $3.295-40.108$ & - & - \\
\hline
\end{tabular}

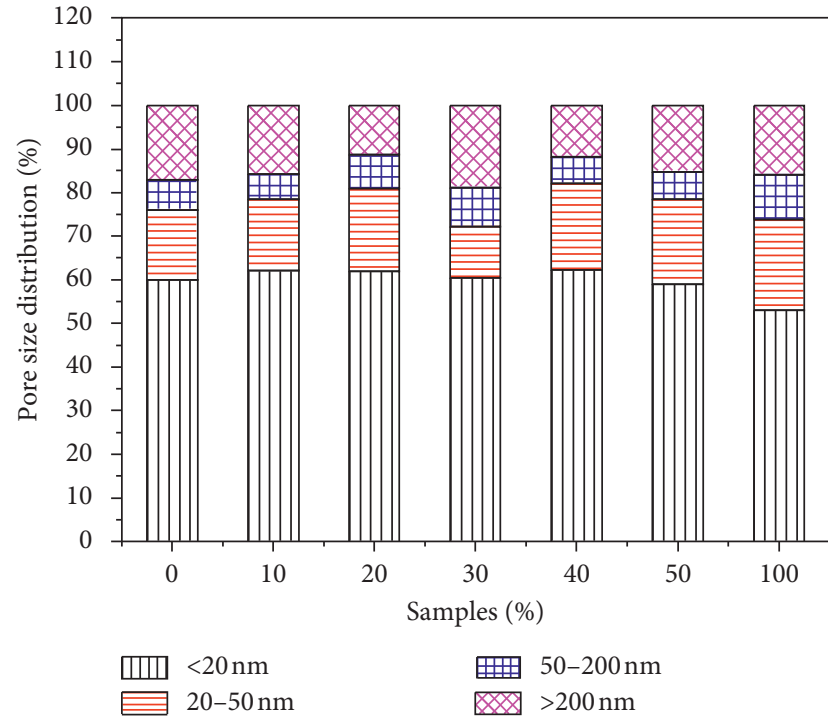

Figure 9: Classification of concrete pore size.

To analyze this problem conveniently, we defined a new variable named harmful pores with diameter of at least $20 \mathrm{~nm}$, and its corresponding porosity is called the harmful pore ratio, $n_{\text {har }}$. Figure 6 also presents the harmful pore ratio $\left(n_{\text {har }}\right)$ of each sample after converting from total pore ratio $(n)$. As can be seen from Figure 6, the value of harmful pore ratio $\left(n_{\text {har }}\right)$ also undergoes a process of first decreasing and then increasing as the aeolian sand content increases with a small change, which agrees well with the macrocompressive strength of concrete and just confirms the deduction that the strength of concrete is determined by the distribution of pore size and the total pore ratio discussed above.

The relationship between concrete compressive strength and pore ratio was established empirically based on the strength theory of porous materials, as proposed by Knudsen [32] and in the form shown in equation (2). A linear formula, as an example, was constructed by Hasselman and Fulrath [33] and is listed in equation (3). The relationship between compressive strength and pore ratio in this test is shown in Figure 10. Further analysis shows that there is a linear variation between the compressive strength and harmful pore ratio $\left(n_{\text {har }}\right)$ with a correlation coefficient of $R^{2}=0.934$. The law between the strength and total pore ratio, however, has a low correlation of $R^{2}=0.653$ :

$$
\begin{gathered}
f=k \cdot G^{-a} \cdot e^{-b \cdot n}, \\
f_{c, n}=f_{c, 0} \cdot(1-k n),
\end{gathered}
$$

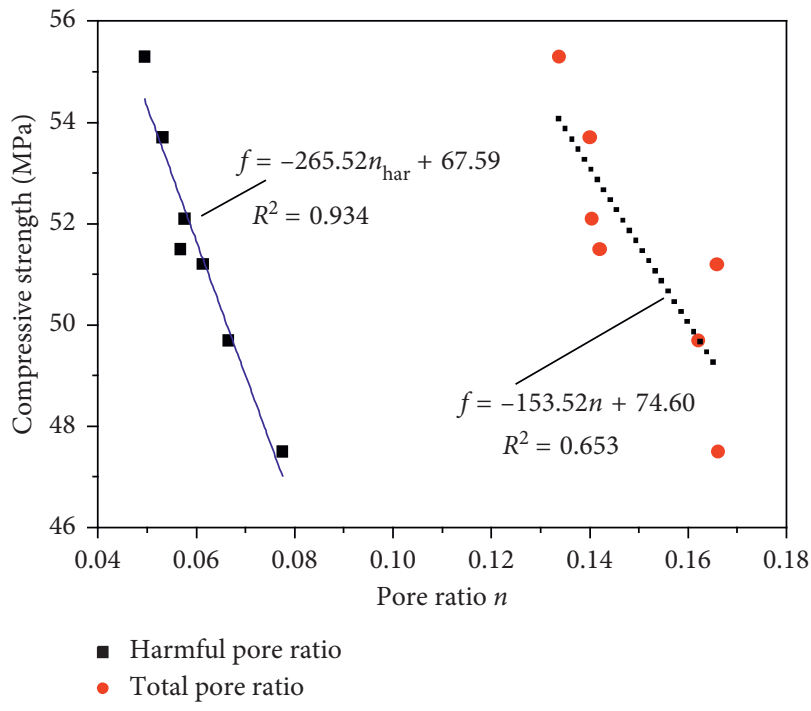

FIgURE 10: Relationship between compressive strength and pore ratio.

where $k, a$, and $b$ are the coefficients; $G$ is the diameter of grain; $n$ is the pore ratio; $f_{c, 0}$ is the strength at a pore ratio of $0 ; f_{c, n}$ is the strength at a pore ratio of $n$.

3.3.2. XRD Result of ASC. The composition and amount of the phase can reflect the influence of aeolian sand content on the cement hydration degree and the strength change of concrete. A representative sample of detrital, with the stones removed, ground into powder, passed through a 200-mesh sieve, and then scanned by an X-ray single crystal diffractometer (voltage: $40.0 \mathrm{kV}$; current: $30 \mathrm{~mA}$; scan speed: $8.0000 \mathrm{deg} / \mathrm{min}$ ) after 28 -day curing, was collected. The phase analysis was carried out based on Guettal and Mezghiche [11] and the analysis of MDI Jade. The result is shown in Figure 11, and for the convenience of analysis, the data have been normalized.

It is easy to see that the samples show dispersive peaks instead of strong, sharp ones at $2 \theta=15^{\circ}-55^{\circ}$, and the phase compositions are mainly $\mathrm{SiO}_{2}, \mathrm{C}-\mathrm{S}-\mathrm{H}, \mathrm{C}-\mathrm{H}, \mathrm{C}_{3} \mathrm{~S}$, and $\mathrm{C}_{2} \mathrm{~S}$, even though the relative content is different. Only the $\mathrm{C}-\mathrm{H}$, $\mathrm{C}-\mathrm{S}-\mathrm{H}$, and $\mathrm{SiO}_{2}$ content, which best reflect the degree of cement hydration and effect of volcanic ash, were analyzed here.

Further analysis shows that the diffraction patterns show wide, poor peaks of C-S-H at $2 \theta$ around $29^{\circ}, 32^{\circ}$, and $50^{\circ}$ and mainly semicrystalline C-S-H (I) based on Chang and Fang [34]. The C-H crystal takes the diffraction peaks of its own at $2 \theta$ near $18.1^{\circ}, 34.1^{\circ}, 47.6^{\circ}$, and $50.8^{\circ}$, respectively. Considering 


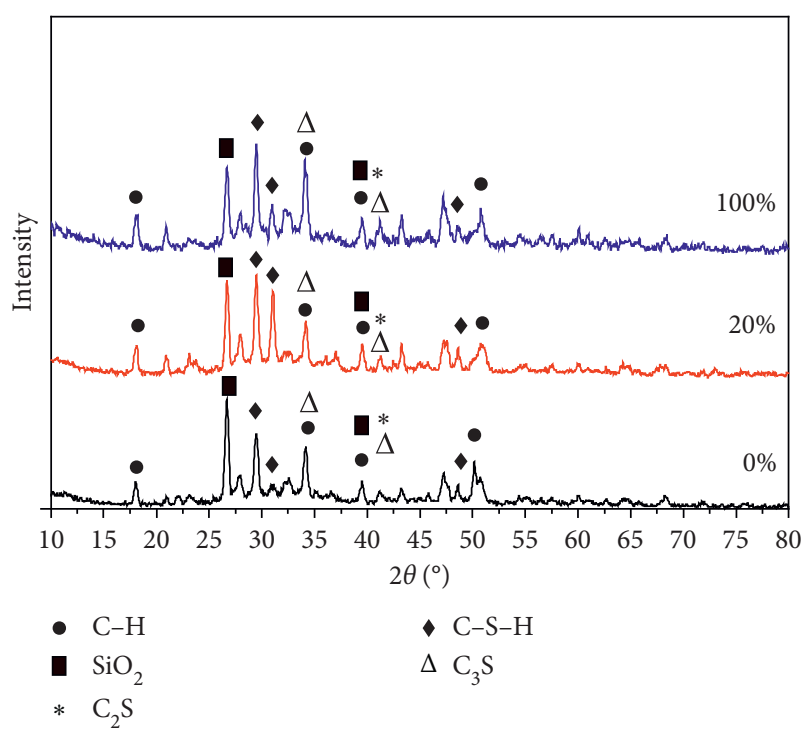

Figure 11: X diffractograms of samples at a curing age of 28 days.

the crystallinity of hydration product was low, the relative content of each hydration product was semiquantitatively characterized by the characteristic peak area [35]. The results show that the relative content of C-H in sample A $(0 \%)$ was the lowest, and its value increased with the increase of aeolian sand content. The sample G (100\%) had the highest value, and the characteristic peaks all appear around $34.1^{\circ}$.

For C-S-H gelation, with the different intensities and peak shapes, the characteristic peak of each sample appeared around $29.1^{\circ}$. Samples A (0\%) and G (100\%) have the characteristic peak near $29.1^{\circ}$ and other smaller peaks; sample C (20\%), which indicated the finer C-S-H gelation may be formed than other samples, shows a substrong peak near $31.8^{\circ}$. As for the content of C-S-H, it increased first and then slow down, with the increase of aeolian sand content, and the difference between $100 \%$ and $20 \%$ was very small. Meanwhile, the content of $\mathrm{SiO}_{2}$ gradually decreased with the increase in aeolian sand content. This indicates that addition of aeolian sand can change both the reaction speed of cement hydration and the relative content of hydration products.

The reason for the different contents of hydration products, such as C-H, C-S-H and the active oxide $\mathrm{SiO}_{2}$ in each sample, is that the aeolian sand has heterogeneous nucleation and volcanic ash effect $[12,18]$. It is equivalent to form new composite cement when adding an appropriate amount of small aeolian sand particles because of its large specific surface area; especially when the size is less than $175 \mu \mathrm{m}$ (whose specific surface area is as high as $7707 \mathrm{~kg} / \mathrm{m}^{2}$ [12]). These active particles (taking $\mathrm{SiO}_{2}$ as its main component) will have a pozzolanic effect in the alkaline environment of $\mathrm{C}-\mathrm{H}$ formed by cement hydration, thereby speeding up the reaction of cement hydration and the formation of high alkalinity C-S-H and C-A-H; meanwhile, the formed C-S-H further reacts with $\mathrm{SiO}_{2}$ to produce the low alkalinity and more stable shape of C-S-H [36, 37], so the average compressive strength of cement paste is increased [11]. This just explains the main reason for the decrease of $\mathrm{SiO}_{2}$ content and the small difference of the maximum peak intensity between the $20 \%$ and $100 \%$ sample in Figure 11 . The possible chemical reaction formulas are as follows, and the hydrolysis and hydration process are roughly shown in Figure 12.

$$
\begin{aligned}
& \quad(0.8-1.5) \mathrm{Ca}(\mathrm{OH})_{2}+\mathrm{SiO}_{2}+\left[\mathrm{n}-(0.8-1.5) \mathrm{H}_{2} \mathrm{O}\right] \\
& \quad \longrightarrow(0.8-1.5) \mathrm{CaO} \cdot \mathrm{SiO}_{2} \cdot n \mathrm{H}_{2} \mathrm{O} \\
& x(1.5-2.0) \mathrm{CaO} \cdot \mathrm{SiO}_{2} \cdot \mathrm{nH}_{2} \mathrm{O}+\mathrm{ySiO}_{2} \\
& \quad \longrightarrow z\left[(0.8-1.5) \mathrm{CaO} \cdot \mathrm{SiO}_{2} \cdot \mathrm{nH}_{2} \mathrm{O}\right] \\
& \mathrm{Al}_{2} \mathrm{O}_{3}+m \mathrm{Ca}(\mathrm{OH})_{2}+y \mathrm{H}_{2} \mathrm{O} \longrightarrow m \mathrm{CaO} \cdot \mathrm{Al}_{2} \mathrm{O}_{3} \cdot y \mathrm{H}_{2} \mathrm{O}
\end{aligned}
$$

For the content of $\mathrm{C}-\mathrm{H}$, which did not decrease but even increased after the volcanic ash reaction, may be attributed to two reasons. One is that the aeolian sand itself is weakly alkaline [7], which increases the alkalinity of the hydration environment; the other is that hydration generation speed of $\mathrm{C}-\mathrm{H}$ is faster than that of consumption speed. In addition, fine particles such as aeolian sand have an effect of heterogeneous nucleation and strong water absorption. When added, it not only shorts the distance between the nucleation site and the cement particles but also reduces the energy barrier of hydration products nucleating on the surface of aeolian sand probability, which can accelerate the nucleation rate of hydration products [38] and affect the macroscopic strength of concrete further.

\section{Time-Varying (Strength-Age) Model of ASC}

With increased time, there are changes in the compressive strength of the concrete. For practical use, it is necessary to describe its growth law by an accurate mathematical method, such as a strength-age model of concrete made of aeolian sand. Larrard [39], the first person to consider the effect of aggregate size on concrete strength, established a compressive strength prediction model as shown in equation (5). This equation considers the maximum paste thickness (MPT); however, the hydration kinetic parameter $(A .1 g(t / 28))$ is empirical and has no upper limit. Ding et al. [40] built a strength-age model of concrete prepared from manufactured sand based on the compressive strength of concrete at 28 days (as shown in equation (6)), which agrees well with indoor test results, but does not converge. The American Concrete Institute (ACI) [41] recommends using equation (7) to predict the strength of concrete at different ages. Unfortunately, there are few reports of a compressive strength time-varying model of ASC. Thus, our goal was to construct and test a strength-age formula of ASC based on the ordinary concrete model and test results considering the harmful pore patio variation and heterogeneous nucleation effect:

$$
\begin{aligned}
& f_{\mathrm{cu}}(t)=\alpha \cdot f_{\mathrm{ce}, 28}\left[A \cdot \lg \left(\frac{t}{28}\right)+c_{0}^{2.85}\right] \cdot \mathrm{MPT}^{-0.13}, \\
& f_{\mathrm{cu}}(t)=5.08 f_{\mathrm{ce}, 28}\left[C \cdot \lg \left(\frac{t}{28}\right)\right] \cdot\left(1+0.001 \rho \frac{m_{\mathrm{w}}}{m_{\mathrm{c}}}\right)^{-1.89},
\end{aligned}
$$




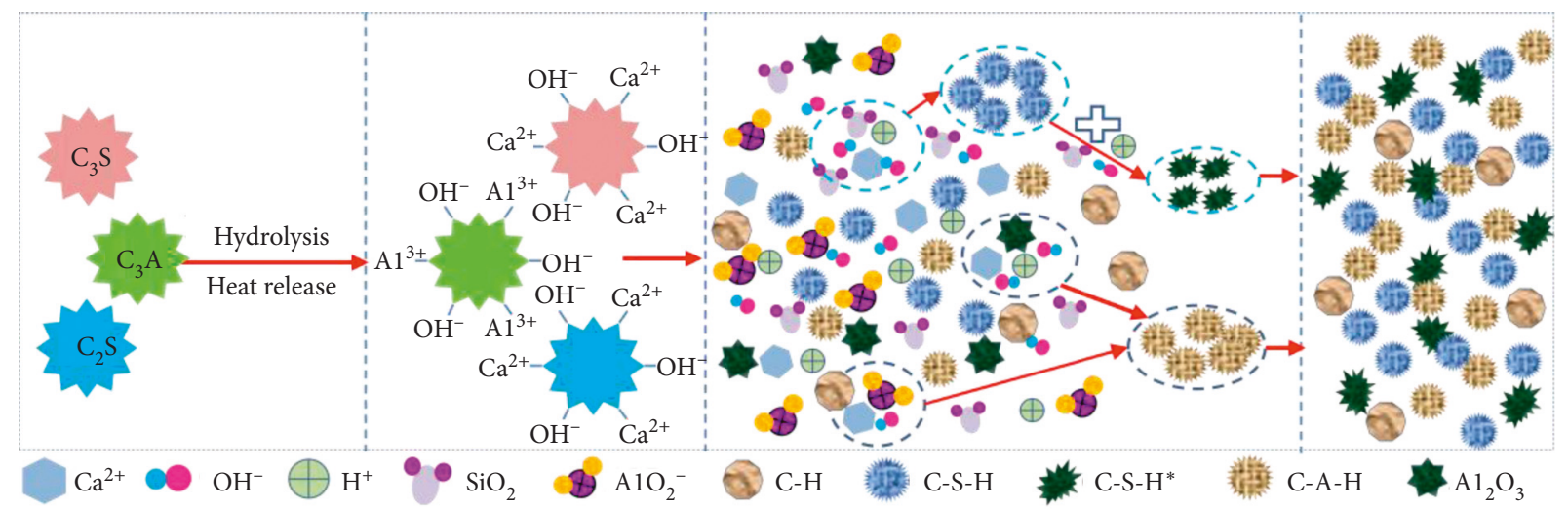

FiguRE 12: Diagram of the cement hydrolysis and hydration reaction process.

$$
f_{\mathrm{cu}}(t)=\frac{t}{A+B t} f_{\mathrm{cu}, 28}
$$

where $f_{\mathrm{cu}}(t)$ is the compressive strength of concrete at $t$ days, $\mathrm{MPa} ; \alpha$ is the test coefficient; $c_{0}$ is the cement concentration of fresh concrete, $c_{0}=V_{\mathrm{c}} /\left(V_{\mathrm{c}}+V_{\mathrm{w}}+V_{\mathrm{a}}\right) ; V_{\mathrm{c}}$, $V_{\mathrm{w}}$, and $V_{\mathrm{a}}$ are the volume of cement, water, and air, respectively; $f_{\mathrm{ce}, 28}$ is the compressive strength of cement at 28 days, $\mathrm{MPa} ; f_{\mathrm{cu}, 28}$ is the compressive strength of concrete at 28 days, $\mathrm{MPa}$; $t$ is the curing age, days; $A, B$, and $C$ are the regression coefficient of test; $\rho_{c}$ is the density of cement; $m_{\mathrm{w}} / m_{\mathrm{c}}$ is the water to cement ratio; MPT is the maximum paste thickness related to the size of coarse aggregate.

\subsection{Assumption}

(1) The effect of aeolian sand content on the compressive strength of concrete can be measured by the physical filling effect (change of the harmful pore ratio) and the volcanic ash and heterogeneous nucleation effect. These two effects do not influence each other.

(2) The strength of ordinary concrete increasing with the curing age $t$ can be written in equation (7). For ASC, the relationship between the strength and curing age can be written as equation (8); the compressive strength of concrete at 28 days $\left(f_{\mathrm{cu}, 28}\right)$ can be calculated by equation (9) [39]:

$$
\begin{aligned}
f_{\mathrm{cu}, \mathrm{ASC}}(t) & =\frac{t}{A+B t} \cdot\left(f_{\mathrm{cu}, 28}+\Delta f_{\mathrm{P}}+\Delta f_{\mathrm{H}}\right), \\
f_{\mathrm{cu}, 28} & =a \cdot f_{\mathrm{ce}, 28} \cdot c_{0}^{n},
\end{aligned}
$$

where $\Delta f_{\mathrm{P}}$ is the strength increment of concrete at 28 days caused by the harmful pore ratio change; $\Delta f_{\mathrm{H}}$ is the strength increment of concrete at 28 days caused by the heterogeneous nucleation and pozzolanic effect; $f_{\mathrm{cu}, \mathrm{ASC}}(t)$ is the compressive strength of ASC at $t$ days, $\mathrm{MPa} ; \alpha$ and $n$ are the coefficient determined by test.

(3) $\Delta f_{\mathrm{P}}$ is caused by the change of harmful pore ratio $n_{\text {har }}$.
(4) $\Delta f_{\mathrm{H}}$ is caused by the volcanic ash and heterogeneous nucleation effects of the VFPs (with a particle diameter of less than $175 \mu \mathrm{m})$ contained in aeolian sand $[12,42]$.

\subsection{Modeling of ASC}

4.2.1. Definition of the Material Physical Properties. Cement with a quality of $m_{\mathrm{c}}$ and a density of $\rho_{c}$; water with a quality of $m_{\mathrm{w}}$ and a density of $1000 \mathrm{~kg} / \mathrm{m}^{3}$; sand with a total quality of $m_{\mathrm{s}}$, an aeolian sand content (mass percentage) of $S$, and a pass rate of $175 \mu \mathrm{m}$ sieve $\left(A_{\mathrm{VFP}}\right)$ per unit volume of concrete are defined in this model.

4.2.2. Calculation of $\Delta f_{P}$. Combining the empirical formula of Hasselman and Fulrath [33] and the experimental results shown in Figure 10, we assume that the $\Delta f_{\mathrm{P}}$ changes via a linear rule with $\Delta n_{\text {har }}$ as shown in

$$
\Delta f_{\mathrm{P}}=D \cdot \Delta n_{\mathrm{har}}
$$

where $D$ is the test coefficient.

4.2.3. Calculation of $\Delta f_{H}$. Previous studies have shown that particles with a diameter of less than $175 \mu \mathrm{m}$ contained in aeolian sand can exhibit volcanic ash and heterogeneous nucleation, which will lead to an increase of the concrete strength at 28 days as shown in the following equation [12]:

$$
\Delta f_{\mathrm{H}}=C \cdot\left(1+\frac{280}{S_{\text {eff }}}\right)^{-1},
$$

where $C$ is the coefficient and $S_{\text {eff }}$ is the effective replacement area of aeolian sand and can be defined by the following equation [12]:

$$
S_{\text {eff }}=S_{S} \cdot\left[\frac{p}{100 \%-p} \cdot \psi(p)\right],
$$

where $S_{S}$ is the specific surface area of VFPs contained in aeolian sand and $p$ is the effective replacement ratio of aeolian sand and can be defined by the following equation [12]: 


$$
p=\frac{m_{\mathrm{VFP}}}{m_{\mathrm{VFP}}+m_{\mathrm{c}}},
$$

where $m_{\mathrm{c}}$ is the quality of the cement. $m_{\mathrm{VFP}}$ is the quality of the VFPs contained in the aeolian sand and can be calculated by

$$
m_{\mathrm{VFP}}=\mathbf{S} \cdot m_{\mathrm{s}} \cdot A_{\mathrm{VFP}} \cdot
$$

Thus, equation (13) can be expressed as

$$
p=\frac{\mathbf{S} \cdot m_{\mathrm{s}} \cdot A_{\mathrm{VFP}}}{\mathrm{S} \cdot m_{\mathrm{s}} \cdot A_{\mathrm{VFP}}+m_{\mathrm{c}}} .
$$

$\psi(p)$ is the efficiency coefficient, as calculated by

$$
\psi(p)=\left[\frac{1+\cos (\pi \cdot p)}{2}\right]^{0.7} \cdot\left[1+\left(\frac{p}{36.8}\right)^{3.4}\right]^{-1} .
$$

Finally, $S_{\text {eff }}$ can be written as equation (17), and equation (11) can be written as equation (18):

$$
\begin{aligned}
S_{\mathrm{eff}} & =S_{\mathrm{s}} \cdot \frac{\mathbf{S} \cdot m_{\mathrm{s}} \cdot A_{\mathrm{VFP}}}{m_{\mathrm{c}}} \cdot\left[\frac{1+\cos \left(\pi \cdot\left(\mathbf{S} \cdot m_{\mathrm{s}} \cdot A_{\mathrm{VFP}} /\left(\mathbf{S} \cdot m_{\mathrm{s}} \cdot A_{\mathrm{VFP}}+m_{\mathrm{c}}\right)\right)\right.}{2}\right]^{0.7} \cdot\left\{1+\left[\frac{\mathbf{S} \cdot m_{\mathrm{s}} \cdot A_{\mathrm{VFP}}}{36 \cdot 8 \mathbf{S} \cdot\left(m_{\mathrm{s}} \cdot A_{\mathrm{VFP}}+m_{\mathrm{c}}\right)}\right]^{3.4}, \quad(17)\right. \\
\Delta f_{\mathrm{H}} & =\mathbf{D} \cdot\left\{1+280 \cdot \frac{m_{\mathrm{c}}}{S_{\mathrm{s}} \cdot \mathbf{S} \cdot m_{\mathrm{s}} \cdot A_{\mathrm{VFP}}} \cdot\left[\frac{2}{1+\cos \left(\pi \cdot\left(\mathbf{S} \cdot m_{\mathrm{s}} \cdot A_{\mathrm{VFP}} /\left(\mathbf{S} \cdot m_{\mathrm{s}} \cdot A_{\mathrm{VFP}}+m_{\mathrm{c}}\right)\right)\right)}\right]^{0.7} \cdot\left\{1+\left[\frac{\mathbf{S} \cdot m_{\mathrm{s}} \cdot A_{\mathrm{VFP}}}{36 \cdot 8 \mathbf{S} \cdot\left(m_{\mathrm{s}} \cdot A_{\mathrm{VFP}}+m_{\mathrm{c}}\right)}\right]^{3.4}\right\}\right\}^{-1} \cdot
\end{aligned}
$$

4.2.4. Calculation of $f_{c u, 28}$. The cement concentration defined in equation (5) $\left(c_{0}=V_{\mathrm{c}} /\left(V_{\mathrm{c}}+V_{\mathrm{w}}+V_{\mathrm{a}}\right)\right)$ can be expressed as a mass ratio of $c_{0} \approx\left(1+0.001 \rho_{\mathrm{c}} m_{\mathrm{w}} / m_{\mathrm{c}}\right)^{-1}$ when ignoring the volume of air, so the concrete compressive strength model at 28 days given in equation (9) is built as the following equation [40]:

$$
f_{\mathrm{cu}, 28}=\alpha \cdot f_{\mathrm{ce}, 28} \cdot c_{0}^{n} \approx \alpha \cdot f_{\mathrm{ce}, 28} \cdot\left(1+0.001 \rho_{\mathrm{c}} \cdot \frac{m_{\mathrm{w}}}{m_{\mathrm{c}}}\right)^{-n} \text {. }
$$

Substituting equation (19) into equation (7), a new compressive strength time-varying model of ordinary concrete is established as

$$
f_{\mathrm{cu}}(t)=\frac{t}{A+B t} \cdot \alpha \cdot f_{\mathrm{ce}, 28} \cdot\left(1+\frac{\rho_{\mathrm{c}}}{1000} \cdot \frac{m_{\mathrm{w}}}{m_{\mathrm{c}}}\right)^{-n} .
$$

Meanwhile, we obtained the final strength-age model of ASC shown as equation (21) by substituting equations (10), (18), and (20) into equation (8).

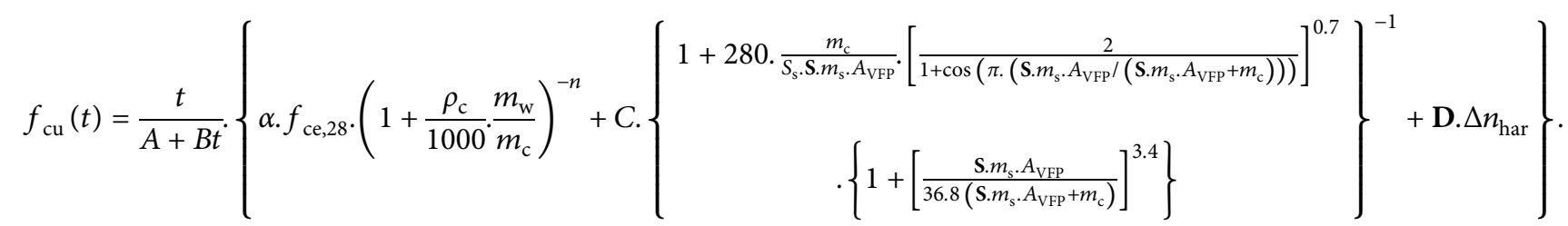

Equation (21) meets the three characteristics of the timevarying (strength-age) model of concrete as follows [41]:

(1) The initial strength value of 0 , which means the curve passes through the point of $(0,0)$

(2) The first derivative of the curve is continuous

(3) The strength increases monotonically and its value is convergent

In equation (21), the coefficients $\alpha, n, A$, and $B$ are independent with the amount of aeolian sand. $C$ and $D$ are related to the aeolian sand content, and other parameters are physical properties of the materials. It is easy to obtain the compressive strength of concrete mixed with different amounts of aeolian sand at any time by using this equation.

\subsection{Parameters Determination}

4.3.1. Values of $\alpha$ and $n$ Contained in $f_{c u, 28}$. There are two coefficients $a$ and $n$, which are needed to be determined to easily acquire the compressive strength of concrete at 28 days. In this work, 15 groups of authors' test data and 50 groups of other scholers' test data [43-46] which include the cement density $\left(\rho_{\mathrm{c}}\right)$, water-cement ratio $\left(m_{\mathrm{w}} / m_{\mathrm{c}}\right)$, compressive strength of cement at 28 days $\left(f_{\mathrm{ce}, 28}\right)$, and other parameters were collected (including 46 groups of river sand, 19 groups of sea sand, cement type covers P. O42.5, P. O42.5R, P. O32.5 with densities of $2970-3150 \mathrm{~kg} / \mathrm{m}^{3}$; fineness modulus of the sand ranged from 2.75 to 3.34 ; watercement ratio changed from 0.39 to 0.82 ; coarse aggregate particle sizes changed from 5 to $31.5 \mathrm{~mm}$; compressive 
strength of $f_{\mathrm{cu}, 28}$ ranged from 21.2 to $64.47 \mathrm{MPa}$ and $f_{\mathrm{ce}, 28}$ from 34.8 to $56.1 \mathrm{MPa}$ ) for the determination of $\alpha$ and $n$ values. When $\alpha=5.35$ and $n=1.98$, the calculated value of concrete compressive strength agrees well with the experimental value, with a correlation coefficient of $R^{2}=0.953$ by regression analysis; the result is shown in Figure 13. Thus, equation (19) becomes equation (22). Using this formula, $f_{\mathrm{cu}, 28}$ can be conveniently calculated if only the $f_{\mathrm{ce}, 28}, \rho_{\mathrm{c}}$, and $m_{\mathrm{w}} / m_{\mathrm{c}}$ are known:

$$
f_{\mathrm{cu}, 28}=5.35 f_{\mathrm{ce}, 28}\left(1+0.001 \rho_{\mathrm{c}} \cdot \frac{m_{\mathrm{w}}}{m_{\mathrm{c}}}\right)^{-1.98} .
$$

4.3.2. Values of $A$ and $B$ in $f_{c u}(t)$. Constants $A$ and $B$ $(A+28 B=28)$ in the hydration kinetics equation $d(t)$ are time dependent. We randomly selected 20 groups of 160 data (M13-M33 from Lea's work [47]) and subjected these data to numerical fitting. The results indicated that $A=3.64$ and $B=0.870$, and the calculated value of concrete compressive strength showed good agreement with the experimental value $\left(R^{2}=0.945\right)$, as shown in Figure 14 . Thus, a compressive strength time-varying model of ordinary concrete is built as shown in

$$
f_{\mathrm{cu}}(t)=\frac{5.35 t}{3.64+0.870 t} \cdot f_{\mathrm{ce}, 28} \cdot\left(1+\frac{\rho_{\mathrm{c}}}{1000} \cdot \frac{m_{\mathrm{w}}}{m_{\mathrm{c}}}\right)^{-1.98} \text {. }
$$

4.3.3. Values of $C$ and $D$ in $f_{c u, A S C}(t)$. According to the laboratory test results (NMR) and semiquantitative analysis by XRD, the aeolian sand can change the pore structure and the hydration products content of concrete. We next determined the value of coefficients $C$ and $D$ based on the test data in Figure 4 . We found that $C=1.37$ and $D=-288.43$ are the optimal solutions for the model, and these theoretical values agree well with the tested value $\left(R^{2}=0.953\right)$, as shown in Figure 15.

Finally, the compressive strength time-varying model of concrete prepared with aeolian sand was built, as shown in equation (24), by substituting the determined values of $\alpha, n$, $A, B, C$, and $D$ into equation (21):

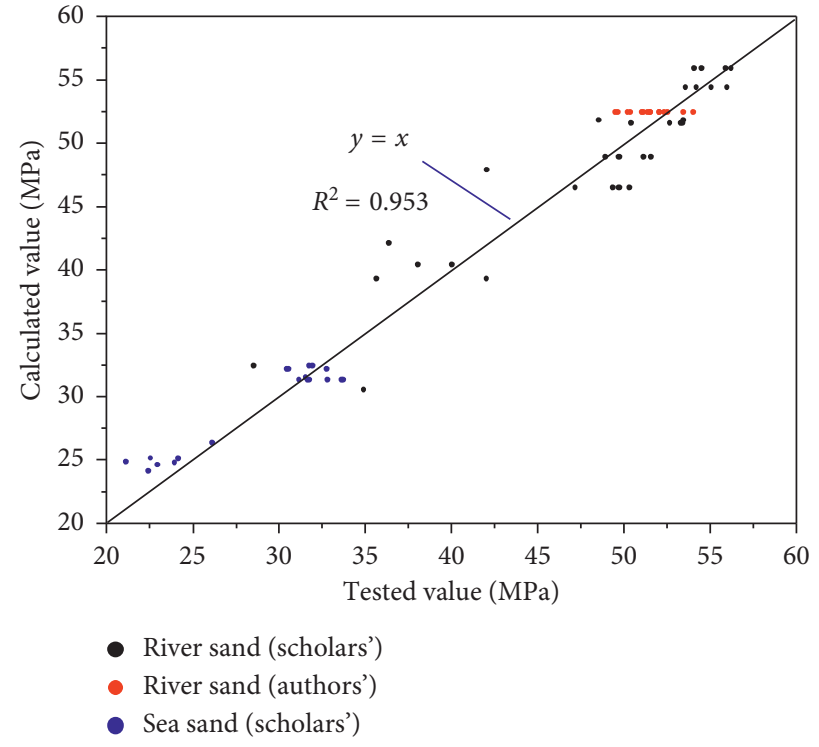

Figure 13: Comparison of calculated values and tested values of $f_{\mathrm{cu}, 28}$.

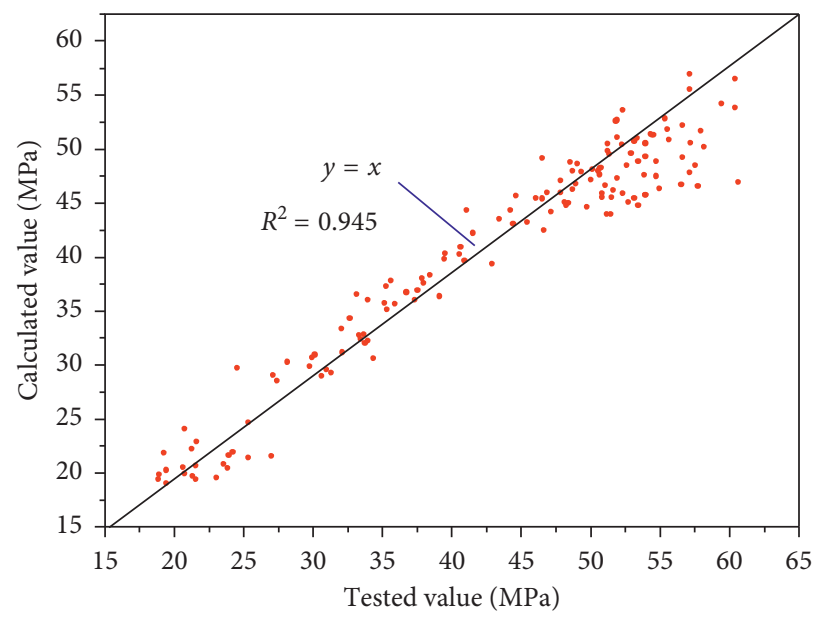

Figure 14: Comparison of calculated values and tested values of $f_{\mathrm{cu}}(t)$.

$$
\begin{aligned}
& f_{\mathrm{cu}, \mathrm{ASC}}(t)=\frac{t}{3.64+0.870 t} \cdot\left\{5.35 f_{\mathrm{ce}, 28} \cdot\left(1+\frac{\rho_{\mathrm{c}}}{1000} \cdot \frac{m_{\mathrm{w}}}{m_{\mathrm{c}}}\right)^{-1.98}\right. \\
& \left.+1.37\left\{\begin{array}{c}
1+280 \cdot \frac{m_{\mathrm{c}}}{s_{\mathrm{s}} \mathrm{S} \cdot m_{\mathrm{s}} \cdot A_{\mathrm{VFP}}} \cdot\left[\frac{2}{1+\cos \left(\pi \cdot\left(\mathrm{S} \cdot m_{\mathrm{s}} \cdot A_{\mathrm{VFP}} /\left(\mathrm{S} \cdot m_{\mathrm{s}} \cdot A_{\mathrm{VFP}}+m_{\mathrm{c}}\right)\right)\right)}\right]^{0.7} \\
\cdot\left\{1+\left[\frac{\mathrm{S} \cdot m_{\mathrm{s}} \cdot A_{\mathrm{VFP}}}{36 \cdot 8\left(\mathrm{~S} \cdot m_{\mathrm{s}} \cdot A_{\mathrm{VFP}}+m_{\mathrm{c}}\right)}\right]^{3.4}\right\}
\end{array}\right\} .288 .43 \Delta n_{\mathrm{har}}\right\} .
\end{aligned}
$$




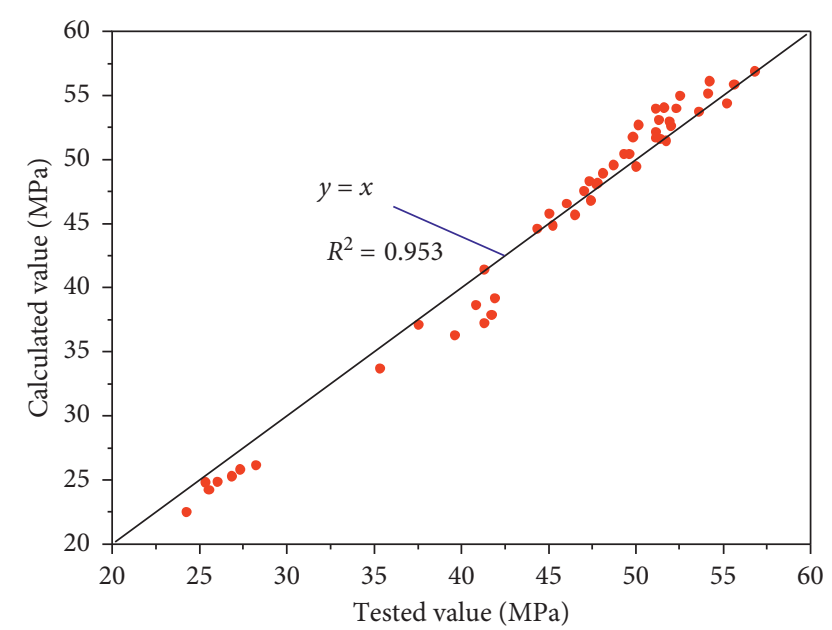

Figure 15: Comparison of calculated values and tested values of ASC's $f_{\mathrm{cu}}(t)$.

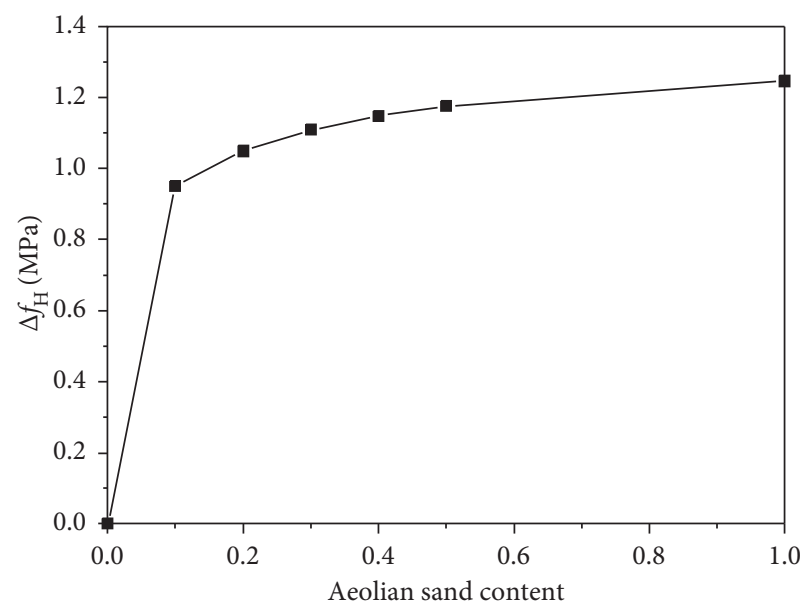

FIgURE 16: Relation between $\Delta f_{\mathrm{H}}$ and aeolian sand content.

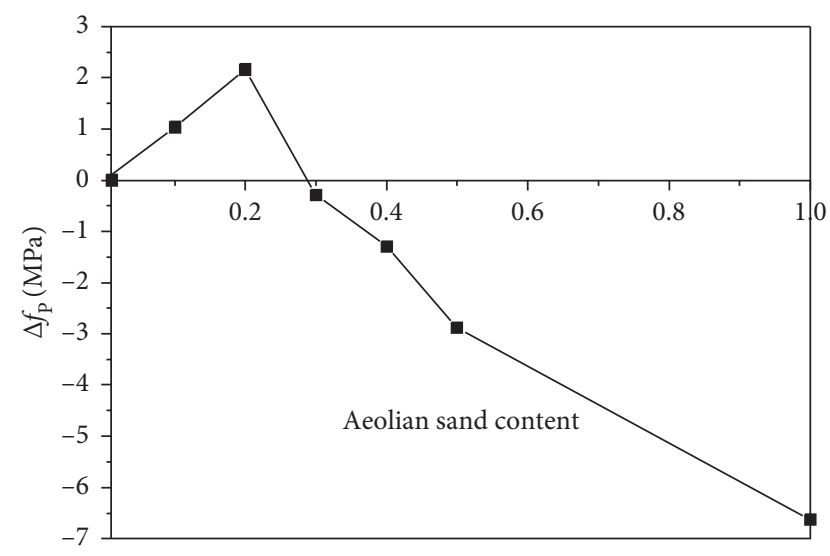

Figure 17: Relation between $\Delta f_{\mathrm{P}}$ and aeolian sand content.

Using equation (24), it is easy to predict the compressive strength of the ASC at any time. Meanwhile, we can calculate the effects caused by the volcanic ash and heterogeneous nucleation $\left(\Delta f_{\mathrm{H}}\right)$, as well as the physical filling $\left(\Delta f_{\mathrm{P}}\right)$ at 28 days, respectively. For this test, the results are shown in Figures 16 and 17.

As can be seen in Figure 16 that the $\Delta f_{\mathrm{H}}$ increases slowly with increased content of aeolian sand, with a maximum value of $1.25 \mathrm{MPa}$, which indicates the volcanic and heterogeneous nucleation effect has small influence on the strength of ASC. The $\Delta f_{\mathrm{P}}$ shown in Figure 17 was due to the change of harmful pore ratio $n_{\text {har }}$ and first increased and then decreased with the aeolian sand content change. This is the main influence on concrete strength with aeolian sand content exceeding $40 \%$.

\section{Conclusions}

In this paper, the influence mechanism of aeolian sand on the strength of concrete was revealed. A compressive strength forecast model of ASC considering the harmful pore ratio variation and heterogeneous nucleation effect was established. The main conclusions are as follows:

(1) The addition of the aeolian sand had a double effect (positive and negative) on the compressive strength of concrete, where the best replacement was $20 \%$. At this ratio, the strength of concrete is $15 \%$ higher than that of the ordinary concrete at a curing age of three days, $11 \%$ higher at seven days, $8 \%$ higher at 28 days, and $6.7 \%$ at 42 days.

(2) The physical and primary mechanism why aeolian sand improved the strength of concrete can be attributed to the change of the internal pore structure and the width of ITZ in concrete, especially the content of the harmless pores.

(3) The chemical mechanism for the improvement of concrete was that the VFPs in the aeolian sand can play a role of heterogeneous nucleation and pozzolanic effect, which changed the content and structure of hydration products.

(4) The strength development of ASC is similar to the ordinary concrete with curing ages. The theoretical model established in this study agrees well with the test results and can easily predict the strength of concrete mixed with different amounts of aeolian sand.

\section{Data Availability}

The data used to support the findings of this study are available from the corresponding author upon request.

\section{Conflicts of Interest}

The authors declare no conflicts of interest.

\section{Acknowledgments}

This study was supported by the National Natural Science Foundation of China under Grant No. 51868075. 


\section{References}

[1] C. Cao and Y. H. Li, "Crazy aggregates," China Economic Weekly, vol. 18, pp. 28-32, 2014, in Chinese.

[2] M. Macfarlane and P. Mitchell, "Scoping and assessment of the environmental and social impacts of river mining in jamaica," in Proceedings of the MERN Working Paper (No. 322003), University of Warwick, England, UK, January 2003.

[3] G. P. Padmakumar, K. Srinivas, K. V. Uday et al., "Characterization of aeolian sands from Indian desert," Engineering Geology, vol. 139-140, pp. 38-49, 2012.

[4] ESS A. Seif, "Performance of cement mortar made with fine aggregates of dune sand, Kharga Oasis, Western Desert, Egypt: an experimental study," Jordan Journal of Civil Engineering, vol. 7, no. 3, pp. 270-284, 2013.

[5] M. G. M. Elipe and S. López-Querol, "Aeolian sands: characterization, options of improvement and possible employment in construction-the State-of-the-art," Construction and Building Materials, vol. 73, pp. 728-739, 2014.

[6] H. F. Liu, J. R. Ma, Y. Y. Wang, and J. Ning, "Influence of desert sand on the mechanical properties of concrete subjected to impact loading," Acta Mechanica Solida Sinica, vol. 30, no. 6, pp. 583-595, 2017.

[7] B. H. Jin, J. X. Song, and H. F. Liu, "Engineering characteristics of concrete made of desert sand from Maowusu Sandy Land," Applied Mechanics and Materials, vol. 174-177, pp. 604-607, 2012.

[8] G. Zhang, J. Song, J. Yang, and X. Liu, "Performance of mortar and concrete made with a fine aggregate of desert sand," Building and Environment, vol. 41, no. 11, pp. 1478-1481, 2006.

[9] S. E. E. Khay, N. J. Jamel, and L. L. Z. Amara, "Compacted dune sand concrete for pavement applications," Proceedings of the Institution of Civil Engineers-Construction Materials, vol. 164, no. 4, pp. 87-93, 2011.

[10] A. S. Al-Harthy, M. A. Halim, R. Taha, and K. S. Al-Jabri, "The properties of concrete made with fine dune sand," Construction and Building Materials, vol. 21, no. 8, pp. 1803-1808, 2007.

[11] S. Guettala and B. Mezghiche, "Compressive strength and hydration with age of cement pastes containing dune sand powder," Construction and Building Materials, vol. 25, no. 3, pp. 1263-1269, 2011.

[12] F. J. Luo, L. He, Z. Pan, W. H. Duan, X. L. Zhao, and F. Collins, "Effect of very fine particles on workability and strength of concrete made with dune sand," Construction and Building Materials, vol. 47, no. 5, pp. 131-137, 2013.

[13] W.-H. Wang, L.-H. Han, W. Li, and Y.-H. Jia, "Behavior of concrete-filled steel tubular stub columns and beams using dune sand as part of fine aggregate," Construction and Building Materials, vol. 51, pp. 352-363, 2014.

[14] Q.-X. Ren, K. Zhou, C. Hou, Z. Tao, and L.-H. Han, "Dune sand concrete-filled steel tubular (CFST) stub columns under axial compression: experiments," Thin-Walled Structures, vol. 124, no. 3, pp. 291-302, 2018.

[15] Ministry of Housing and Urban-Rural Development of the People's Republic of China, JGJ 55-2011, Specification for Mix Proportion Design of Ordinary Concrete, China Building Industry Press, Beijing, China, 2011.

[16] Ministry of Housing and Urban-Rural Development of the People's Republic of China, GB/T 50081-2002, Standard for Test Method of Mechanical Properties on Ordinary Concrete, China Building Industry Press, Beijing, China, 2002.
[17] B. Tayeb, B. Madani, and H. Mourad, "Effect of dune sand on the properties of flowing sand-concrete (FSC)," International Journal of Concrete Structures and Materials, vol. 6, no. 1, pp. 59-64, 2012.

[18] W. Dong, X.-d. Shen, H.-j. Xue, J. He, and Y. Liu, "Research on the freeze-thaw cyclic test and damage model of aeolian sand lightweight aggregate concrete," Construction and Building Materials, vol. 123, pp. 792-799, 2016.

[19] Y. A. Yusuf and A. Billihaminu, "Comparative study on strength properties of concrete made with river sand and dune sand as fine aggregate," IOSR Journal of Mechanical and Civil Engineering, vol. 12, no. 4, pp. 71-75, 2015.

[20] Y. G. Li, X. L. Ma, D. W. Hu et al., "Influence of aeolian sand content on mechanism of mortar and concrete," Bulletin of the Chinese Ceramic Society, vol. 36, no. 6, pp. 2128-2133, 2017, in Chinese.

[21] M. A. Neville, Properties of Concrete, Pearson, London, UK, 1973.

[22] H. F. Liu, J. R. Ma, J. Fu et al., "Research on the mechanical properties of desert sand concrete," Concrete, vol. 9, pp. 8086, 2015, in Chinese.

[23] R. M. E. Valckenborg, L. Pel, K. Hazrati, K. Kopinga, and J. Marchand, "Pore water distribution in mortar during drying as determined by NMR," Materials and Structures, vol. 34, no. 10, pp. 599-604, 2001.

[24] R. Y. Wang, X. D. Shen, H. J. Xue et al., "Mechanism research on wind-sand erosion and freeze-thaw coupling damage of pumice concrete," Journal of Basic Science and Engineering, vol. 27, no. 2, pp. 418-429, 2019, in Chinese.

[25] P. K. Mehta, "Studies on blended Portland cements containing Santorin earth," Cement and Concrete Research, vol. 11, no. 4, pp. 507-518, 1981.

[26] H. G. Xu, Z. P. Li, F. Z. Bi et al., "Research on the pore structure of concrete in dry climate and big temperature change," Journal of Wuhan University of Technology, vol. 29, no. 9, pp. 101-103, 2007, in Chinese.

[27] Z. W. Wu, "An approach to the recent trends of concrete science and technology," Journal of the Chinese Ceramic Society, vol. 7, no. 3, pp. 262-270, 1979, in Chinese.

[28] M. Mohammadi, R. Mir Moghtadaei, and N. Ashraf Samani, "Influence of silica fume and metakaolin with two different types of interfacial adhesives on the bond strength of repaired concrete," Construction and Building Materials, vol. 51, no. 31, pp. 141-150, 2014.

[29] D. X. Xuan, Z. H. Shui, and S. P. Wu, "Influence of silica fume on the interfacial bond between aggregate and matrix in nearsurface layer of concrete," Construction and Building Materials, vol. 23, no. 7, pp. 2631-2635, 2009.

[30] Y. Xie, D. J. Corr, F. Jin, H. Zhou, and S. P. Shah, "Experimental study of the interfacial transition zone (ITZ) of model rock-filled concrete (RFC)," Cement and Concrete Composites, vol. 55, no. 55, pp. 223-231, 2015.

[31] Y. L. Chen, Z. H. Zheng, H. Q. Shao et al., "Research on asymmetry of interfacial transition zone in concrete," Journal of Wuhan University of Technology, vol. 29, no. 9, pp. 111-114, 2007.

[32] F. P. Knudsen, "Dependence of mechanical strength of brittle polycrystalline specimens on porosity and grain size," Journal of the American Ceramic Society, vol. 42, no. 8, pp. 376-387, 1959.

[33] D. P. H. Hasselman and R. M. Fulrath, "Effect of small fraction of spherical porosity on elastic moduli of glass," Journal of the American Ceramic Society, vol. 47, no. 1, pp. 52-53, 1964. 
[34] J. Chang and Y. Fang, "Quantitative analysis of accelerated carbonation products of the synthetic calcium silicate hydrate (C-S-H) by QXRD and TG/MS," Journal of Thermal Analysis and Calorimetry, vol. 119, no. 1, pp. 57-62, 2015.

[35] R. Talero, L. Trusilewicz, A. Delgado et al., "Comparative and semi-quantitative XRD analysis of Friedel's salt originating from pozzolan and Portland cement," Construction and Building Materials, vol. 25, no. 5, pp. 2370-2380, 2011.

[36] W. C. Dong, D. J. Kang, and L. J. Wang, "Review on the volcanic ash effect of fly ash in fly ash concrete," Science and Technology of Overseas Building Materials, vol. 25, no. 3, pp. 28-31, 2004, in Chinese.

[37] W. Dong, X. D. Shen, Y. J. Lin et al., "Impact of mixed aeolian sand on the properties of pumice lightweight aggregate concrete," Bulletin of the Chinese Ceramic Society, vol. 34, no. 8, pp. 2089-2094, 2015, in Chinese.

[38] P. Lawrence, M. Cyr, and E. Ringot, "Mineral admixtures in mortars effect of type, amount and fineness of fine constituents on compressive strength," Cement and Concrete Research, vol. 35, no. 6, pp. 1092-1105, 2005.

[39] F. D. Larrard, Concrete Mixture Proportioning: A Scientific Approach, Spon press, London, UK, 1999.

[40] X. Ding, C. Li, Y. Xu, F. Li, and S. Zhao, "Experimental study on long-term compressive strength of concrete with manufactured sand," Construction and Building Materials, vol. 108, pp. 67-73, 2016.

[41] American Concrete Institute, 209R-1, Prediction of Creep, Shrinkage and Temperature Effects in Concrete Structures, ACI Committee Press, Farmington Hills, MI, USA, 1992.

[42] M. Cyr, P. Lawrence, and E. Ringot, "Efficiency of mineral admixtures in mortars: quantification of the physical and chemical effects of fine admixtures in relation with compressive strength," Cement and Concrete Research, vol. 36, no. 2, pp. 264-277, 2006.

[43] H. P. Bi, "Experimental study on the effect of water cement ratio on pavement performance of cement concrete," Engineering and Test, vol. 51, no. 2, pp. 32-34, 2011, in Chinese.

[44] N. Jee, S. Yoon, and H. Cho, "Prediction of compressive strength of in-situ concrete based on mixture proportions," Journal of Asian Architecture and Building Engineering, vol. 3, no. 1, pp. 9-16, 2004.

[45] H. Yiğiter, H. Yazıcı, and S. Aydın, "Effects of cement type, water cement ratio and cement content on sea water resistance of concrete," Building and Environment, vol. 42, no. 4, pp. 1770-1776, 2007.

[46] E. Yaşar, Y. Erdoğan, and A. Kılıç, "Effect of limestone aggregate type and water-cement ratio on concrete strength," Materials Letters, vol. 58, no. 5, pp. 772-777, 2004.

[47] C. Peter Hewlett, Lea's Chemistry of Cement and Concrete (Chapter 6), Elsevier Butterworth-Heinemann, New York, NY, USA, 2005. 


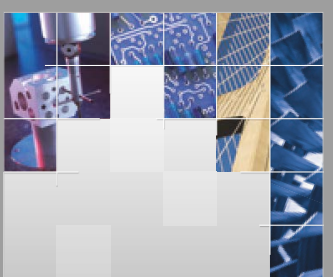

\section{Enfincering}
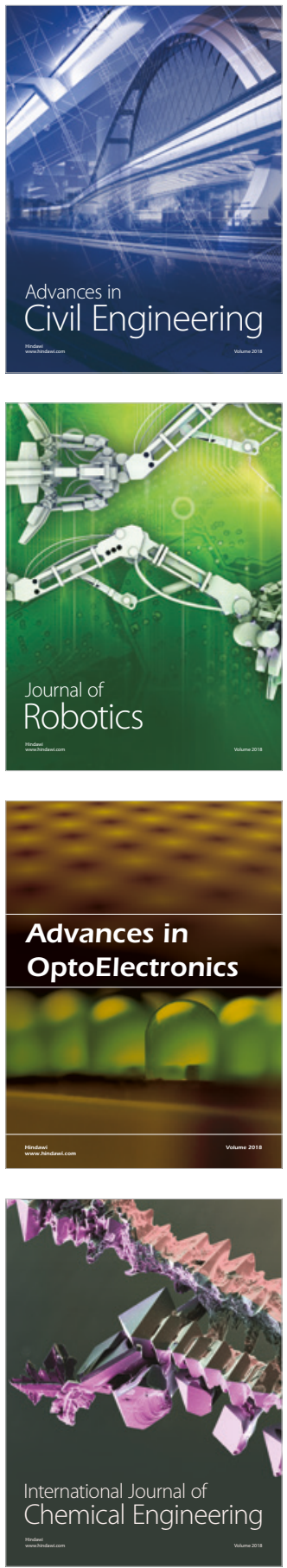

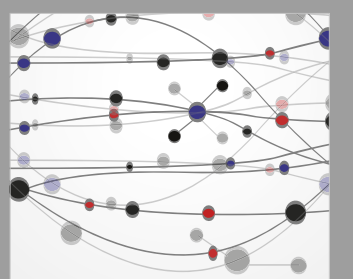

\section{Rotating \\ Machinery}

The Scientific World Journal

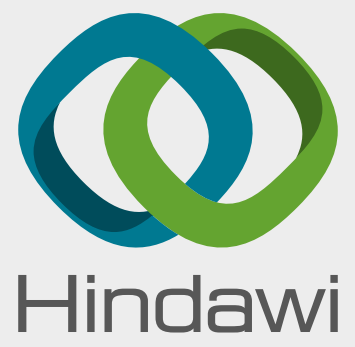

Submit your manuscripts at

www.hindawi.com
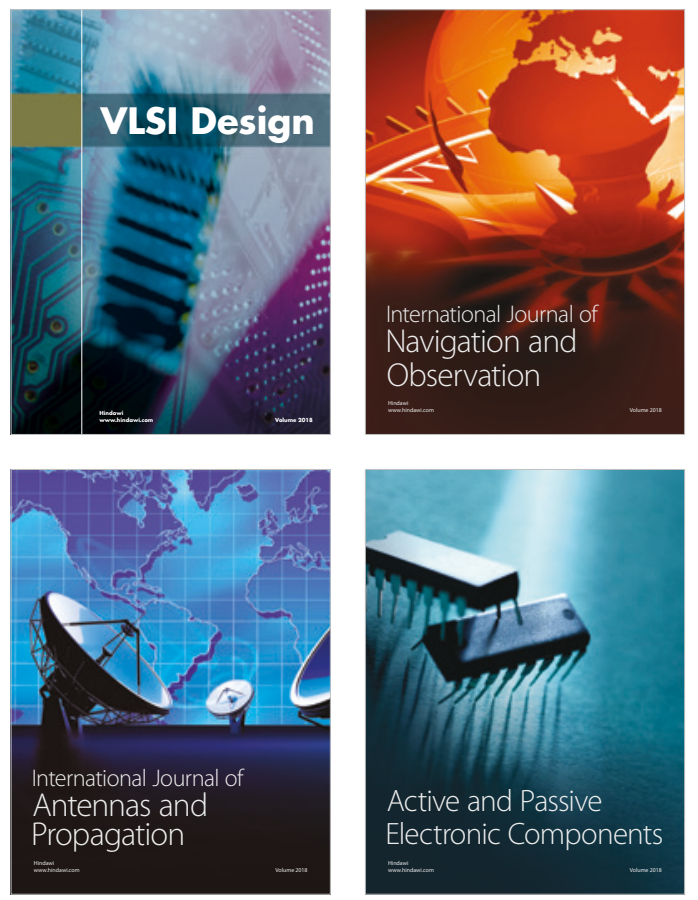
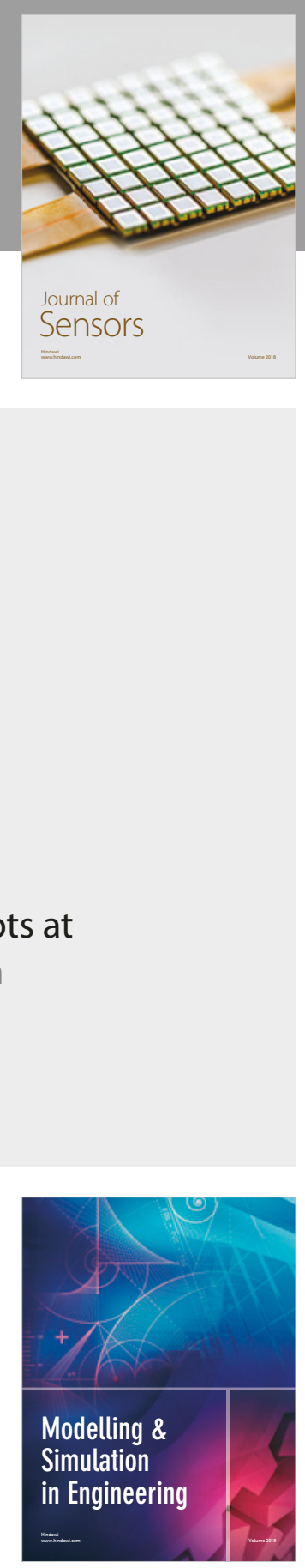

\section{Advances \\ Multimedia}
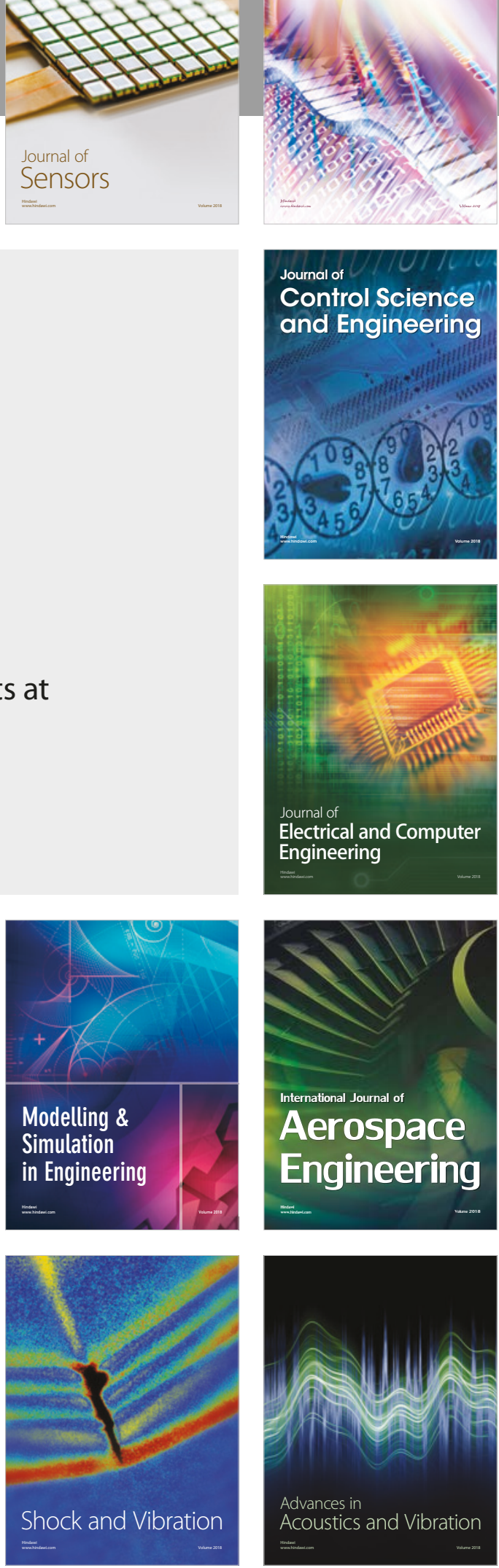